\title{
THE EFFECTS OF STATE SCOPE OF PRACTICE LAWS ON THE LABOR SUPPLY OF ADVANCED PRACTICE REGISTERED NURSES
}

\author{
Sara Markowitz \\ E. Kathleen Adams \\ Working Paper 26896 \\ http://www.nber.org/papers/w26896 \\ NATIONAL BUREAU OF ECONOMIC RESEARCH \\ 1050 Massachusetts Avenue \\ Cambridge, MA 02138 \\ March 2020
}

Funding for this research was provided by AHRQ grant 1R01HS024530. We thank Mark Votruba, Nathan Petek and seminar participants at Indiana University, Louisiana State University, and the ASHEcon conference for extremely helpful comments. The views expressed herein are those of the authors and do not necessarily reflect the views of the National Bureau of Economic Research.

NBER working papers are circulated for discussion and comment purposes. They have not been peer-reviewed or been subject to the review by the NBER Board of Directors that accompanies official NBER publications.

(C) 2020 by Sara Markowitz and E. Kathleen Adams. All rights reserved. Short sections of text, not to exceed two paragraphs, may be quoted without explicit permission provided that full credit, including $\odot$ notice, is given to the source. 
The Effects of State Scope of Practice Laws on the Labor Supply of Advanced Practice Registered Nurses

Sara Markowitz and E. Kathleen Adams

NBER Working Paper No. 26896

March 2020

JEL No. I1,J01,K0

\begin{abstract}
$\underline{\text { ABSTRACT }}$
This paper studies the effects of changes in states' scope of practice laws (SOP) for advanced practice registered nurses (APRNs) on individual labor supply decisions. Restrictive SOP impose costs and other barriers to practice that may affect these decisions. Using survey data on APRNs, we analyze employment in nursing, work hours, part-time work status, multiple job holding, selfemployment, wages, and migration. Results show that the level of SOP restrictions are not strong determinants of many labor market decisions, with a few exceptions. We find that hours worked and self-employment both increase when nurses practice in regulatory environments that are free from physician oversight requirements.
\end{abstract}

Sara Markowitz

Department of Economics

Emory University

Rich Memorial Building

1602 Fishburne Dr.

Atlanta, GA 30322

and NBER

sara.markowitz@emory.edu

E. Kathleen Adams

Emory School of Public Health

1518 Clifton Road, NE

Atlanta, GA 30322

eadam01@emory.edu 


\section{INTRODUCTION}

In 2017, national health care expenditures were \$3.5 trillion, representing $17.9 \%$ of the U.S. gross domestic product (Martin et al. 2019). This level of expenditure has been criticized by many as too high, especially when compared to other developed nations where health care spending typically ranges from 8-12\% of GDP and health outcomes are no worse or better (OECD 2018). As national efforts to reduce the growth in health care spending have stalled, finding productivity gains within the existing system may be a viable path forward. Twenty percent of national health care expenditures are spent on professional services making this sector an important area to explore for efficiency gains (Martin et al. 2019).

This paper focuses on scope of practice (SOP) laws and the labor market for advanced practice registered nurses (APRNs). APRNs are nurses with advanced degrees, usually a master's degree, who practice in one of four roles: certified nurse anesthetists (CNA), certified nurse-midwives (CNM), clinical nurse specialists (CNS) and nurse practitioners (NP). APRNs are currently a small proportion of the health care workforce but serve in important roles. APRNs are trained to perform many of the same tasks as certain types of physicians including examinations, diagnoses, providing treatments and prescribing medicine. They may serve as complements to or substitutes for physicians.

The labor markets for APRNs are influenced by barriers in the form of licensing requirements prior to entry, and scope of practice laws post entry. Licensing provisions ensure that health care practitioners are well-trained and serve to protect the public from harm. These requirements are generally not controversial. However, the same cannot be said for scope of practice laws. Scope of practice laws are the legal authority given to licensed health care professionals to provide medical services once in practice. These laws specifically define the 
practitioners’ roles, articulate oversight requirements (if any), and govern practice and prescriptive authorities. The practice environment established by SOP laws can vary dramatically based on the state in which the APRN practices. In many states, the scope of practice laws can be considered as highly restrictive and certain aspects of these laws can impose significant costs on practitioners. These costs have the potential to affect the functioning and efficiency of APRN labor markets.

Over time, restrictive SOP laws have become controversial and their utility placed in question. The oversight provisions of SOP laws are justified as a way to further protect the public health and ensure quality of care. However, research has shown no evidence of better health outcomes achieved under a strict oversight environment, rather, evidence is mounting that these laws instead raise costs and restrict access to care. See Adams and Markowitz (2018) for a review of this literature. Given the evidence that less restrictive laws do not affect the quality of care, the remaining questions include what inefficiencies are created and what types of market distortions do these laws impose.

The purpose of this paper is to analyze the effects of changes in certain aspects and of the restrictiveness of states' scope of practice laws on individual labor supply decisions of APRNs. We use pooled cross sections of individual-level data and state-level data on SOP laws to analyze a number of different APRN labor market outcomes that may be affected by the costs and barriers imposed by restrictive SOP laws. Specifically, we analyze the probability of employment in nursing, number of hours worked, part-time versus full-time work, the probability of working multiple jobs, the probability of self-employment, wages, commuting across state lines for work, and changing job location to a different state. We show that on average, APRNs do not alter many aspects of their labor supply decisions in response to changes 
in the state SOP environment with the exception of work hours. We also find that nurses working in states without oversight requirements are much more likely to be self-employed. These results have implications for the functionality of local labor markets which in turn may affect patient access to these health care providers.

\section{SOP LAWS AND LABOR SUPPLY DECISIONS}

Scope of practice laws are the legal authority given to health care providers to provide medical services, and for APRNs, the laws govern both practice and prescriptive authorities. The practice environment for APRNs located in different states can vary dramatically based on these laws. In some states, APRNs are required to practice and prescribe under physician oversight. This oversight may be supervisory, delegative, or collaborative in nature, however all require a formal agreement to practice with physicians. These oversight laws effectively tie the APRN practice to physicians and can set up significant barriers to practice, described in detail below. Other states have moved to "full practice authority" (FPA) where APRNs practice without any legal requirements for a formal relationship with physicians.

Although states vary widely in the provisions detailed by their SOP laws, many of the restrictive SOP laws share common features including collaborative practice agreements and protocols. A collaborative practice agreement (CPA) is a written statement that defines the joint practice of an APRN and a physician. The CPA specifies the rights and responsibilities of each party along with the requirements for physician consultation. Some states require written protocols as part of the CPA. These outline the specific details of the APRN practice such as the medical conditions the APRN may treat, the treatments that may be provided, and the drug therapies that may be prescribed. 
The oversight requirements present in the SOP laws can impose different types of costs on APRNs, potentially altering labor supply decisions. These costs can be analyzed within the standard labor-leisure framework. Note that the following discussion pertains only to the decisions that correspond to the individual-level data we analyze. Other researchers have presented theoretical and empirical analyses of the effects of SOP laws on market-based outcomes including labor substitution and provider mix, measures of productivity, and prices (see for example, Wing and Marier’s 2014 study on dental services and Richards and Polsky’s 2016 study on Medicaid patients).

For states with SOP laws requiring some form of formal relationship between the APRN and physician, APRNs will face costs associated with setting up and maintaining a collaborative practice agreement. First, the APRNs will face time and money search costs to find a collaborating physician. These search costs may be higher in states with articulated restrictions on the physician-to-nurse ratio for oversight. For example, states such as Alabama and California allow each physician to oversee at most four APRNs. Search costs can be viewed as one-time fixed costs that affect reservation wages, discourage entry into the APRN labor market, and may encourage migration to states with lower entry barriers. These search costs may also promote job-lock among employed APRNs.

Upon finding a collaborating physician, APRNs may face monetary costs in the form of fees to set up and maintain the CPA. In a 2017 survey of APRNs working in states that require CPAs, Martin and Alexander (2019) find that 22 percent of APRNs reported paying a fee to establish a CPA and 24 percent reported paying a fee to maintain the CPA. The median establishment fee was $\$ 650$, but ranged from $\$ 10$ to $\$ 50,000$ across individuals. The median maintenance fee was lower at $\$ 500$ per month, with a range of $\$ 4$ to $\$ 4,167$ per month. Since 
these fees typically do not vary with wages, they induce pure income effects that alter reservation wages and entry and exit decisions. In addition, APRNs already in the labor market would have an incentive to increase the hours supplied of work if leisure is a normal good. APRNs who work multiple jobs are required to have separate CPAs with each physician, imposing additional search and monetary costs for these workers.

Psychic costs are another consideration. The oversight requirements mandated by SOP laws can generate greater disutility from work for APRNs as some will dislike working under strict oversight conditions. Having to stick within the strict protocols or not having prescriptive authority may contribute to disutility as well. Conversely, some workers may feel more comfortable with such oversight and not face these costs. In general, psychic costs result in differently shaped or placed utility functions, and APRNs who face psychic costs will make consumption and leisure decisions differently from those who do not. This could result in either a reduction in the hours supplied or an exit from the state’s labor market.

Compliance costs are the fourth class of costs we consider. Compliance with SOP regulations means APRNs have to spend work time away from seeing patients to consult physicians and secure their approvals. This issue may be particularly burdensome under the supervisory type of SOP. This can lower the marginal productivity of APRN labor and hence, lower the wage rate. Reductions in wages will discourage labor force participation, but have an ambiguous effect on hours worked that depends on the strength of the income and substitution effects and whether leisure is a normal or inferior good.

To summarize, we expect high search costs and monetary fees resulting from restrictive SOP laws to discourage work and increase the likelihood of migration toward a state with lower costs. Psychic costs and compliance costs will further discourage labor force participation and 
increase migration. Predictions on hours supplied are ambiguous. We cannot disentangle the effects of each different type of costs since workers in states with restrictive SOP face all of these costs simultaneously. Our empirical results will therefore reflect the net effects of changes in these combined costs on the outcomes studied.

The effect of SOP laws on wages warrants further discussion. The relationship between wages and SOP is important to this story since equilibrium wages may also be affected via SOPinduced changes in both the supply of APRNs and the demand for their labor, with the result that the changes in equilibrium market wages are indeterminate. Generally speaking, eliminating regulation increases profitability, and under a FPA environment, demand will increase if the elimination of restrictions on tasks and administrative burdens increases the marginal productivity of APRNs (e.g. the compliance costs story). Demand may also increase if patient tastes for APRN-provided care increase by creating a "seal of approval" from the state. New clinics may open as a result, although it is not clear if this would expand the market or simply generate a substitution from physician-based care. The market-level predictions are complicated by the degree of substitutability among health care professionals, which may vary based on the service under consideration, and by the presence of insurance and reimbursement rules. In particular, the practice of incident-to billing allows office-based services provided by some APRNs to be billed under a physician's national provider identification number and paid according to the Centers for Medicare \& Medicaid Services physician fee schedule. This practice is governed by strict supervisory rules which may render the state legislated SOP irrelevant. See Markowitz and Adams (2018) for details. Overall, the effects on wages of moving from an oversight-based SOP to FPA is theoretically indeterminate. 
In the models described below, we analyze wages and earnings as outcomes along with the other labor market outcomes. The models are all reduced form models and show the total effects of the SOP laws on the outcomes. For the measures of labor supply such as labor force participation and hours worked, the interpretation of the coefficients on the SOP laws should be thought of as working through the direct costs imposed by restrictive SOPs and through any resulting changes in wages.

\section{PREVIOUS LITERATURE}

Only a handful of papers exist that analyze the effects of SOP on labor market outcomes for nurses. Kleiner et al. (2016) is the most closely related paper to ours. The authors use individual-level data on NPs from the American Community Survey (ACS) to analyze the effects of SOP on nurse hourly earnings and hours worked. They analyze practice authority and prescription authority separately in their models, and show that independence in practice authority has no statistically significant effects on NP hours worked, while independent prescription authority is associated with small increases in NP hours worked in the range of 6579 hours per year or 3-4 percent. By contrast, they find that independence in practice authority is associated with an increase in hourly earnings of about 5 percent while finding no effect on earnings associated with independent prescription authority.

Other studies use aggregate data to study the supply of nurses. McMichael (2018) and Xue et al. (2018) both use data from the National Plan and Provider Enumeration System (NPPES), as provided by the Area Health Resource File, to generate county level-rates of NPs supply. McMichael (2018) includes an analysis of the effects of state SOP laws on the number 
of NPs per county with consideration of the level of physician supply. Xue et al (2018) focus their study on the relationship between SOP laws and NP supply in rural and primary care Healthcare Professional Shortage Areas. Both authors find that supply is greater in states with full practice authority. However, the results must be interpreted with caution. Their measure of supply counts NPs with a national provider identification number and includes nurses who are employed, unemployed, and out-of-the-labor force. Since the NPPES does not have a system in place to assure that the provider information is up-to-date and accurate, it is likely that provider counts by state or county are misreported, and the problem worsens as practitioners age (Bindman 2013). It is unknown whether this measurement error is random or correlated with the SOP laws. These issues put in question the usefulness of this data as an accurate measure of nurse employment.

Aggregate data on the number of licensed APRNs is also provided by The Nurse Practitioner. Reagan and Salsberry (2013) use this data to study the association between SOP laws and licensed NPs for the year 2008. Markowitz et al. (2017) also use this source for data on licensed CNMs. Reagan and Salsberry (2013) find that restrictive SOP is associated with lower numbers of NPs and lower growth rates, although the cross-sectional nature of the data limits the ability to draw causal inference. Markowitz et al. (2017) find no relationship between changes in SOP laws and the number of licensed CNMs in an analysis that spans 1999-2013.

Another related paper is that by Perry (2012). While not measuring a labor market outcome directly, Perry studies the effects of SOP laws on the probability of moving residences. This proxies for NPs "voting with their feet” in regards to laws that affect work environment. The measure of SOP used is an indicator of whether a state allows NPs some level of controlled substance prescriptive authority. He concludes that NPs are 3 percentage points less likely to 
move away from a state with some level of controlled substance prescriptive authority, regardless of oversight requirements.

While the existing literature points to the general conclusion that restrictive SOP hinders the market for NP labor in a variety of ways, there is room for improvement. The individuallevel papers by Kleiner et al. (2016) and Perry (2012) focus on limited definitions of SOP. Perry's focus on only prescriptive authority may not adequately summarize the practice environment faced by NPs. Kleiner et al. include measures of practice and prescriptive authority separately which makes interpreting the laws difficult as these authorities may change simultaneously, for example, when states adopt full practice authority. The aggregate-level papers by McMichael (2018) and Xue et al. (2018) avoid this issue and consider both practice and prescriptive authority jointly, however, these papers utilize a measure of supply that may not well reflect the actual labor force. Aggregate-level analyses present the additional problem of policy endogeneity when current supply is regressed on current laws. It is possible that the observed positive relationship is a result of a large presence of nurses with a strong lobbying effort influencing the SOP laws. Individual-level data does not suffer from this policy endogeneity problem.

We advance this literature by using individual-level data on nurses to analyze a number of different labor market outcomes that may be affected by the costs and barriers imposed by restrictive scope of practice laws. Specifically, we analyze the probability of employment in nursing, number of hours worked, part-time versus full-time work, the probability of working multiple jobs, the probability of self-employment, wages, commuting across state lines for work and changing job location to a different state. The SOP laws are defined to consider practice and prescriptive authority simultaneously since both of these are important components of nurses’ 
jobs and often change at the same time. The law categories are defined in terms of a range of potential barriers to care and the costs imposed on nurses. Our conclusions diverge from those presented above. In general, we find that the level of SOP restrictions are not strong determinants of many labor market decisions, with a few exceptions. We find that hours worked and self-employment both increase when nurses practice in regulatory environments free from oversight requirements.

DATA

Our primary data source is the National Sample Survey of Registered Nurses (NSSRN). This survey is conducted approximately every four years between 1977 and 2008 and includes in each iteration nationally representative samples of RNs with active licenses in the United States. We limit the sample to the subset of RNs who are identified by the survey designers as APRNs, based on questions regarding advanced practice education. We use the most recent five years of the data—1992, 1996, 2000, 2004 and 2008. We begin in 1992 since SOP laws at that time are restrictive in most states and there is not much legislative activity prior to then. The survey conducted in 2008 was the last year of this particular survey. While the data are somewhat old, the surveys were conducted during a time when states began moving towards full practice authority, and therefore we observe a lot of variation in the SOP laws during this time (discussed more below). Since APRNs in many states still face restrictions on practice, the lessons from past experiences are relevant for today. An advantage of the NSSRN survey is availability of geographic information on the respondents' state and county of residence and state and county of work. This allows us to identify the proper SOP environment(s) faced by respondents, especially when border crossing is an option. 
Dependent variables: The NSSRN asks a variety of questions regarding nurses' current and past employment situation and location. From these questions we generate a number of dependent variables designed to match closely with the decisions for labor force participation, hours worked, and migration. Table 1 shows means of the dependent variables for the estimation samples of APRNs and NPs, and Table 2 shows the means by SOP law classifications. These laws classifications are described in detail below.

We first examine employment, defined as the probability of currently working as a nurse versus working in another occupation or not working. The survey asks about working status and location in the current survey year (1992, 1996, 2000, 2004 and 2008) and in the past year (1991, 1995, 1999, 2004 and 2007), thus, we can generate probability of working in up to ten years of survey data along with changes in employment status.

Next, we examine the number of hours worked including overtime and on-call work in a typical week in the APRN's principal job, among those currently employed. We also evaluate part-time versus full-time status in primary job. Annual (but not weekly) hours worked in secondary nursing jobs are also collected so we examine total annual hours worked in primary and secondary jobs.

Two additional outcomes of interest among those currently employed are the probability of currently working multiple jobs and the probability of self-employment. SOP requirements for entering into CPAs and the associated fees may make it more costly for APRN to work in multiple jobs or to be self-employed.

The survey asks respondents who are currently employed in nursing for an estimate of gross annual salary/earnings in their principle position. We use responses to this question to reflect earnings. We also generate an estimate of hourly wages by dividing annual earnings by 
the reported number of usual scheduled work hours and the number of weeks normally worked per year in the principle position. There are a few cases where this calculation resulted in extremely low wages that are likely results of reporting or recording errors. To correct for this, we treat wages as missing for the nineteen observations where the calculated hourly wage is less than the federal minimum wage for that year. Wages will also be missing in cases where earnings, hours, or weeks are not reported. Wages and earnings are expressed as real (19821984) dollars. Log real wages and log real earnings are also used, and show similar results as the unlogged values.

The geographic and past-year questions allow us to delve into some types of migration decisions. First, since we know the counties in which the APRN lives and works, we can analyze whether or not an APRN commutes across state lines for work. To do this, we compare the SOP of the resident and border counties to see if living in a more restrictive SOP encourages commuting to a less restrictive environment. When we conduct this analysis, we limit the sample to respondents who live in counties that border counties in another state. County border information comes from the U.S. Census Bureau’s County Adjacency File. Second, the pastyear questions allow us to measure the probability of working in a different state in adjacent years. This migration measure reflects attachment to the local labor force and allows us to test whether the type of SOP in the work location in the past year encourages respondents to change job locations in the subsequent year.

APRN Characteristics: The NSSRN reports a limited number of demographic and personal characteristics. We generate indicator variables for gender, age, race, marital status, and the presence of children in the home. Indicator variables for missing value on these indicators are also included in order to preserve observations. Indicator variables for the 
different types of APRN are also included. An APRN may be trained as a CNA, CNM, CNS or NP, either alone or in combination. In the models based on the employed sample, we also include indicator variables for the employment setting: hospital, nursing home/extended care, nursing education program, public or community health, school health service, occupation health, ambulatory care, all other settings.

SOP Laws: SOP laws are described in state statutes and various years of The Nurse Practitioner. There are a variety of ways to classify the SOP laws with the result that many different researchers have utilized different schemes. It is common in the academic literature to separate practice and prescription authorities (see for example Kleiner et al. 2016; Kurtzman et al. 2017) or to study only one of the authorities (Stange 2014; Timmons 2017). The problem with the first approach is that the laws can be highly collinear since the two authorities are often changed at the same time. The problem with the second approach is that independence in one authority may still be limiting in terms of the day-to-day practice if the other authority is not granted. In the past, a number of states have granted independence in practice authority yet required some form of physician oversight if prescription authority is desired. These states include Hawaii, Michigan, New Mexico, Oklahoma, Rhode Island, Utah, and West Virginia. In cases like these, the APRN is effectively under an oversight regime since she cannot practice up to the level of her training. For this reason, practitioner groups such as the American Association of Nurse Practitioners (AANP) consider both authorities when describing in their classifications of the laws. We do the same in our classification as described below.

Our classification of the laws is designed to reflect the potential costs imposed on an APRN to keep the discussion in line with the labor supply decisions. Before describing our classification scheme, some definitions are helpful here. Recall that a CPA is a written statement 
signed by the APRN and physician that specifies the rights and responsibilities of each party along with the requirements for physician consultation. Written protocols may be part of the CPA and outline the specific details of the APRN practice. Search costs and practice agreement fees will be relevant for any state law that requires a CPA. CPAs and protocols may affect productivity and impose compliance costs that rise as the degree of required physician involvement rises. Psychic costs can also vary along the different practice and authority limitations. Regarding prescription authority, state law may limit the types of drug therapies included in this authority. Prescription drugs are classified into two main groups of controlled and non-controlled substances. Controlled substances are further classified into schedules that range from Schedule I to Schedule V in declining order of the potential for abuse. Other noncontrolled substances that still require a prescription have a low potential for abuse and include drugs such as antibiotics, asthma medications, insulin, and blood pressure medications. As with CPAs and protocols, limits on prescribing may increase psychic costs and compliance costs.

Given these considerations, we define five categories of SOP laws as follows:

1) Full practice authority (FPA) -- states that grant full practice and prescription authorities and may encourage collaboration in statute but neither require collaborative practice agreements nor articulate practice protocols.

2) Collaborative Practice Agreement (CPA) -- states that require CPAs but no written protocols and have full prescription authority for non-controlled drugs and controlled substances up to schedule II or III.

3) Protocols -- states that require CPAs and written practice protocols. APRNs can prescribe non-controlled drugs and controlled substances up to schedules II or III. 
4) Protocols, limited RX - states that require CPAs and written practice protocols. APRNs are allowed to prescribe non-controlled drugs and may be allowed to prescribe schedule IV or V drugs but no schedule II or III controlled substances.

5) Supervision, no RX - states require APRNs practice under physician supervision or delegation with no prescribing privileges. Any prescribing is done via order or delegation from a physician.

Over time, states have generally followed a progression of changes in the restrictiveness of the laws. In the early 1990s when our data collection begins, many states required APRNs to practice under the supervision of a physician and did not allow prescription authority. Since then, states have adopted new SOP laws that both expand prescription authority and loosen or eliminate the supervisory requirements. Table 3 shows the number of states in each category by survey year and Figure 1 shows maps of these states for each year in our sample. It is evident that the states in our sample time period became less restrictive over time and yet, only twelve states were classified as FPA by 2008. As of January 2020, 27 states can be classified as such (Phillips 2020). Even though the current policy debate surrounds the movement to FPA, our main models will examine the movements across all five categories of SOP laws in order to show whether the degree of restrictiveness matters. These analyses are instructive as many states still have rather restrictive SOP in effect today.

There are a few limitations of our classifications of the SOP laws. First, while APRNs who are required to have a CPA will face the search and money costs associated with finding a collaborating physician, the actual dollar amounts of any fee would be determined on an individual basis. Martin and Alexander (2019) find that the type of employer matters for these fees. APRNs who work for large health care facilities or for privately owned physician practices 
are much less likely to have to pay CPA fees as compared to APRNs working in private practices run by APRNs. Unfortunately, we cannot determine facility ownership from the survey data. Second, the SOP laws generally pertain to all types of APRNs, however, it is not uncommon for states to have separate SOP for CNMs, CNSs and/or CRNAs. NPs are consistently covered by the laws as coded, and therefore all models are estimated for the full sample of APRNs and for a separate subsample of only NPs. Limiting the sample to NPs reduces sample size but will ensure that the respondent is covered by the law.

State and County characteristics: The models described below include the number of MDs per 1,000 population in the county, defined as the total number of non-Federal MDs in patient care. This variable will help account for the availability of collaborating/supervising physicians in each county. We include the county unemployment rate to account for local labor market conditions. These data are from the Area Health Resource File, and are merged according to either the county of residence or county of work, depending on the outcome being evaluated. All models also include an indicator variable for whether or not the APRN's state of residence is part of the Nurse Licensure Compact (NLC). This compact is an agreement among member states to honor the Registered Nurse (RN) or licensed practical nurse (LPN) license of the home state. This indicator varies over time, with enactment dates taken from DePasquale and Stange (2016). This agreement does not apply to APRN practice, and APRNs must be licensed in each state in which they practice. We include this indicator to help capture some of the potentially unobserved state sentiment towards nurse licensure and regulation in general. 
The general empirical specification models the labor market outcomes as a function of state SOP laws (SOP), individual characteristics $(X)$, employment setting among those employed $(W)$, state/county characteristics $(Z)$, and state $(\delta)$ and year $(\gamma)$ fixed effects. In the models described below $S O P$ is a vector of the state laws, with the least restrictive law, full practice authority, serving as the omitted reference category. All models are estimated first among all APRNs and again for NPs only;

The probability of employment in nursing (Emp) for individual (i) in state of residence (r) at time (t) is estimated as follows:

(1a) $\operatorname{Pr}(E m p)_{\text {irt }}=\beta_{1} S O P_{r t}+\beta_{2} X_{i t}+\beta_{3} Z_{r t}+\delta_{r}+\gamma_{t}+\varepsilon_{j t}$

(1b) $\operatorname{Pr}(\text { Emp })_{\text {irt }}=\beta_{1} \mathrm{SOP}_{r t}+\beta_{2}$ BorderLessRestrictive $_{r t}+\beta_{3}$ BorderSame/MoreRestrictive $_{r t}+$

$$
\beta_{3} X_{i t}+\beta_{4} Z_{r t}+\delta_{r}+\gamma_{t}+\varepsilon_{j t}
$$

In Equation 1a, we include indicator variables for the scope of practice laws pertaining to the state of residence, which may or may not overlap with the state in which an APRN works. To account for the SOP work environment options and for the possibility that a respondent works and lives in different states, in Equation 1b we include indicator variables for the SOP law of border counties. Specifically, we include indicator variables for 1) living in a border county with SOP in the neighboring county less restrictive than the home county (17 percent of the APRN sample); and 2) living in a border county with SOP in the neighboring county the same or more restrictive than the home county (24 percent of the APRN sample). The omitted reference category reflects living in a county that does not border another state (55 percent of the APRN sample). Models estimating the probability of employment are shown using the five years of current survey data and using the full ten years of available data, that is, the five main survey years plus the questions regarding employment status in the previous year. 
Next, we estimate other labor market outcomes $(L)$ among workers:

(2) $\quad L_{i w t}=\beta_{1} S O P_{w t}+\beta_{2} X_{i t}+\beta_{3} W_{i t}+\beta_{4} Z_{w t}+\delta_{w}+\gamma_{t}+\varepsilon_{j t}$

Here, $L$ represents hours worked, part-time versus full-time work, probability of holding multiple jobs, probability of self-employment, annual earnings, or hourly wages. The SOP laws in these analyses pertain to the state in which the APRN or NP holds her primary job (w). Border laws are not relevant here since the APRN has already chosen her work environment. The vector $W$ represents the seven indicator variables for the different employment settings. County characteristics and state fixed effects also pertain to the state of work rather than residence.

The equations for estimating commuting across state lines for work are as follows:

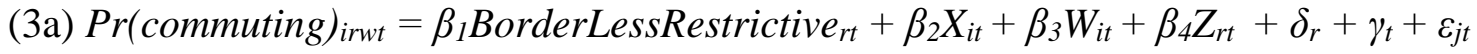
(3b) $\operatorname{Pr}\left({\text { commuting })_{i r w t}=\beta_{1}\left(S_{S O P}{ }^{*} \text { BorderLessRestrictive } r t\right.}\right)+\beta_{2} X_{i t}+\beta_{3} W_{i t}+\beta_{4} Z_{r t}+\delta_{r}+\gamma_{t}+\varepsilon_{j t}$ Here, we limit the sample to those currently employed in nursing and examine whether or not the APRN or NP currently works in a different state than her residence. This equation is estimated only among nurses who live in border counties since this is the group most likely to border cross for work. (Only 2.25 percent of the sample report not living on a border and working across state lines.) Equation 3a shows the effects of living in a county that borders a state with less restrictive SOP. Equation 3b expands on 3a and uses interactions between the SOP of the state of residence and the less restrictive border county indicator. Specifically, these categories are as follows: 1) lives in CPA and borders a less restrictive state (i.e. FPA); 2) lives in Protocol and borders a less restrictive state (i.e. either FPA or CPA); 3) lives in Protocol with limited RX and borders a less restrictive state; and 4) lives in Supervisory with no RX and borders a less restrictive state. The omitted reference category includes individuals living in the same SOP 
environment as the border and individuals living in SOP environments that border more restrictive states. Also included are the individual characteristics, employment setting, county/state characteristics pertaining to the residence, and state and year fixed effects.

The last labor market outcome is migration defined as the probability of working in different states in adjacent years, conditional on working in nursing in both years. This is estimated with the following equation:

(4) $\operatorname{Pr}(\text { change work state })_{i w t}=\beta_{1} S O P_{w(t-1)}+\beta_{2} X_{i t}+\beta_{3} W_{i(t-1)}+\beta_{4} Z_{w(t-1)}+\delta_{w(t-1)}+\gamma_{(t-1)}+\varepsilon_{j t}$ where the subscript $w$ indicates the state of work rather than residence, and SOP laws pertain to the previous year's SOP in the state in which the APRN or NP worked. This equation analyzes the "push" factor and shows whether the SOP environment in the state of work last year is associated with working in a different state in the current year. We do not include border indicators here since the respondents may move to any state for this migration decision.

The above models are all estimated with OLS/LPM with state-clustered standard errors. Where relevant, probit models yield very similar results and are available upon request.

\section{THREATS TO VALIDITY}

Policy endogeneity is one potential threat to validity to this type of difference-indifference analysis. However, we argue that this not an issue here since decisions at the individual-level should not affect the current state laws. The changes in SOP laws often arise from intense lobbying efforts from practitioner groups and the timing of the change in the laws may have more to do with political power and campaign contributions than actual market conditions. Moreover, previous work on SOP laws has found no evidence of policy endogeneity (Kleiner et al. 2016; Markowitz et al. 2017; McMichael 2018; Traczynski and Udalova 2018). 
Another potential threat to validity is the violation of the assumption of parallel trends that underlies difference-in-differences models. The issue in question is whether in the absence of the treatment, the difference in the treatment and control groups follows the same trend over time. The pooled cross-sectional nature of this data along with the three-year gaps between the five survey waves means that we have very few data points with which to examine pre-policy trends. Nevertheless, we present evidence that there is no systematic trend leading up to the states' policy changes. Details are provided below in the "Event Study" section.

\section{RESULTS}

Results from estimating the above equations are presented in Tables 4 through 7. Table 4 shows the results for the probability of employment in nursing as compared to working in a nonnursing occupation or not working. Eighty-nine percent of the sample is employed in nursing, with eight percent not working and the rest working in a non-nursing profession. Some nurses report holding multiple jobs that may include a mix of nursing and non-nursing work. These respondents are coded as employed in nursing. Even though the proportion of nurses employed is 89 percent in both the five year and the 10 year samples, it is useful to analyze both samples since it is different nurses that are employed in each year, as a nurse can change employment status from past to present. About 5.5 percent of the sample changes employment status, and the number who change from employed to not employed (2.8 percent) and vice versa (2.7 percent) is very similar.

Table 4 includes eight columns with the first four using data for all APRNs and the second four using data for NPs. The odd numbered columns show results using the five years of main data, whereas the even numbered show the full ten years of available data based on the 
past-year recall question. Columns 3, 4, 7 and 8 include the indicators for living on the border of a less restrictive state and bordering states that are the same or more restrictive. The omitted reference category is not living on a border. The results are consistent across all these models and show small and statistically insignificant coefficients for the various levels of SOP laws. A similar statement hold for the border indicators.

Interestingly, the indicator variable for the state of residence in the Nurse Licensure Compact is positive and significant in all models. Since this compact pertains only to RN and LPN licenses, this result should be interpreted as reflecting a state environment that generally promotes nurse employment. Another interesting result that arise is that being male increases the probability of employment by about 4 percentage points. Divorced and single respondents are more likely to be employed than married respondents.

Results for hours worked, multiple job holding and self-employment are show in Panel A of Table 5 for all APRNs and Panel B of Table 5 for NPs only. Only the coefficients on the SOP laws, Nurse Licensure Compact, and county characteristics are shown for brevity. The results indicate that respondents living in some of the more restrictive SOP environments work fewer hours. This statement pertains to weekly hours in the primary job and to yearly hours in all jobs combined. Among all APRNs living under supervisory SOP, the magnitude is 2 fewer hours per week and 135 fewer hours per year. The magnitudes are slightly larger for NPs only with a 3 hour weekly reduction for the supervisory SOP and 148 annual reduction. These results are consistent with the findings of Kleiner et al. (2016) who find a reduction in work hours associated with legislated restrictions on prescription authority.

While the SOP laws have no statistically significant effects on the probability of parttime work, nor on the probability of holding multiple jobs, the restrictive SOP laws are 
negatively related to the probability of self-employment. That is, APRNs and NPs who work in restrictive SOP states of any level are less likely to be self-employed than those working in FPA environments. The magnitude of the effect is around 6-7 percentage points for APRNs and ranges from 7 to 10 percentage points for NPs. The proportion of APRNs (NPs) who are selfemployed is 15.6 percent (12.6 percent). The magnitudes of these results are large but are not surprising given that the restrictive SOP laws tie the APRN practice to MDs, making it much more difficult to be self-employed.

Table 6 shows results for real annual earnings and calculated real hourly wages. While almost none of the coefficients show are statistically significant at conventional levels, the coefficients on the four levels of oversight are almost uniformly negative and three of the SOP coefficients in the NP models are significant at the 15 percent significance level. Note that the negative sign on earnings may simply reflect the negative sign estimated for hours worked, but using the calculated wages should isolate the wage effect. Despite the statistical insignificance, the magnitudes are informative. Among all APRNs, wages under oversight environments are reduced by about 2 percent relative to FPA. For NPs only, however, this magnitude rises to a 810 percent difference, or about $\$ 2.00$ per hour. A negative sign here is consistent with the compliance costs story where oversight SOP reduces the marginal productivity of APRN labor and lowers the equilibrium wage rate when any supply response is less than the demand response. While we are not examining aggregate supply in this paper, we do find no meaningful effects of the SOP laws on the probability of employment making the compliance costs story plausible.

Turning to the outcomes related to migration, Table 7 shows results for the probability of commuting, that is, working and living in different states in a given year. The sample is limited 
to only those nurses who live in a border county and includes the results for the main five year sample (columns 1 and 3) and the 10 year sample (columns 2 and 4). The results show that options matter. APRNs living in restrictive SOP environments who border a less restrictive state are more likely to cross the border for work (columns 1 and 2). Results in columns 3 and 4 show that the effect is dominated by APRNs who live in CPA states and border FPA, and by APRNs who live in state with protocols and border either CPA or FPA. These respondents are 8-9 percentage points more likely to commute than respondents living on borders with the same or greater level of restriction. However, these results are sensitive to the sample used (APRNs vs NPs) with the coefficients for NPs generally insignificant, but of similar sign and magnitudes.

Lastly, we estimate the effects of changes in the SOP laws on the probability of working in different states in adjacent years. Here we find that the SOP laws have no statistically significant effects on this migration measure, whether APRNs or just NPs are examined. These results are not shown in a table but are available upon request. Only 562 respondents (5 percent) move work locations, and of the total movers, 163 (29 percent) moved to a work location with the same level of SOP restrictions, 203 (36 percent) moved to a more restrictive SOP and 196 (35 percent) moved to less restrictive SOP. Interestingly, 35 percent keep their residence in the same state and move their jobs to another state, while 65 percent move both jobs and residence. Within these two categories, workers are moving to the same, more, and less restrictive SOP environments in roughly equal proportions. The overall conclusion here is that SOP does not seem to be a factor in moving decisions.

The results in Tables 4, 5, and 6 show the effects of the level of restriction in SOP laws relative to a FPA environment. However, over time there is a lot of movement among the states from a highly restrictive category to a less restrictive category that is not FPA. For example, a 
common move among states is from the category of supervision with no RX to the category of protocols, with sixteen states making this switch. In order to clearly show whether these types of law changes have effects on the outcomes, we rerun select models from Tables 4, 5 and 6, each time changing the omitted reference category. While the magnitudes of these differences could be calculated from the main tables, in Table 8 we present the results using these iterations in order to provide the reader with more easily interpretable comparisons.

Table 8 shows the results from changing the omitted reference category for all APRNs. Results for NPs are similar and available upon request. The outcomes shown are: the probability of employment in nursing (using the current year sample from column 1 in Table 4), hours per week of work in primary job, and the probability of self-employment. The coefficients on the laws for part-time employment, multiple job holding, and real wages are all statistically insignificant, regardless of the omitted category, and are therefore not shown.

A few differences are shown in Table 8 that are not apparent from the main tables. Regarding employment in nursing, APRNs living in CPA states are more likely to be employed than those in protocol states. Similarly, nurses in states with protocols and limited RX are more likely to be employed than those in supervision states. However, an unexpected result is that nurses in states with protocols and limited RX are more likely to be employed than nurses in protocol states. The magnitude of these effects are all fairly small, ranging from 2 to 3 percentage points.

The results for hours of work tend to be concentrated among the categories of supervision and full practice authority, yielding no differences among the intermediate law categories. The results for self-employment are among full practice authority only, with no effects being seen for among the other categories. This result makes a lot of sense in that we would only expect to see 
an increase in self-employment once the nurse practices is untethered to the physician's practice. Overall, the results of this exercise show that not only is the movement to full practice authority important but intermediate steps that move the practice environment away from supervision is also important. The response to switching among the intermediate categories of protocols with limited RX, protocols only, and CPA is fairly limited.

\section{EVENT STUDY}

This section addresses the possible violation of the assumption of parallel trends that underlies the above models. The issue in question is whether in the absence of the treatment, the difference in the treatment and control groups follows the same trend over time. We check for this in two ways: First, we show visual evidence that the trends in the average outcomes of the two group are very similar throughout the time period studied. Second, we conduct a regressionbased event study analysis.

For both of these exercises, we define the treatment group as APRNs in states that experience any change in SOP law between 1992 and 2008, while the control group includes APRNs in states that experience no changes. There are 8 states that change laws twice during the sample period so these states are excluded so that there is no overlap in the pre and post categories. The event time is classified into surveys waves (not years) before and after the law change. For example, for states that experience a law change in the 1993, 1994, or 1995 the data from the 1992 survey comprise the pre-period and event time is coded as " 1 wave prior", while data from survey years 1996, 2000, 2004 and 2008 are the post-periods and are coded as event times 1, 2, 3, and 4 waves post, respectively. The models show a range of three pre-waves to four post-waves. We combine the event year and the first post wave into one reference category 
termed " $0 / 1$ wave post". We do this because of the mix of law changes in survey and non-survey years. Laws are matched to the data as of the beginning of the year so the outcomes are all observed after the law changes.

One issue with these analyses is that a lot of the states change their laws in the earlier years of the data and therefore the number of states that contribute to the pre-period trends is small. Only seven states have a third pre-wave. These are states that passed laws between 2001 and 2007, so there is at least a 9 year gap between the third pre-wave (1992 survey data) and first post-wave. The length of time between each wave should be kept in mind when interpreting these results.

Figure 2 shows visual evidence that the trends in the average outcomes of the two groups are very similar throughout the time period studied. The trends for the control states shown are based on randomly assigned dates of the event. Overall, the trends in the outcomes for the two groups track very closely, with no strong apparent divergence before the events, especially for the first and second pre-waves. The data used to generate Figure 2 pertains to all APRNs. The figures for NPs are very similar and are available upon request.

Figure 3 contains results from the regression-based event analyses for APRNs. Again, results for NPs are similar and are available upon request. The regression models are similar to those in the regression tables, except that the policy indicator is replaced with indicators for the waves before and after any law change as described above. The coefficients and confidence intervals plotted are shown relative to the first post wave. In all models, the coefficients for 1 and 2 waves prior are statistically insignificant, indicating a lack of evidence of confounding pretrends in the recent waves leading up to a law change. However, going back further in time generates a few statistically significant coefficients for two of the ten outcomes: working and 
living in different states and annual hours of work. This is not cause for concern since the third wave prior is measured many years prior to the law change and pertain to very few states. In addition, the average trends shown in Figure 2 for these outcomes do not indicate a problem. Lastly, the insignificant coefficients shown on the post-waves corroborate the insignificant results presented above for many of the outcomes studied.

\section{CONCLUSIONS}

The results of this study show that APRNs do not alter many aspects of their labor supply decisions in response to changes in states' SOP practice environments. The results show no effects of the different levels of restrictiveness in the SOP laws in determining the probability of part-time work, the probability of holding multiple jobs, nor the probability of moving to a different state for work. The probability of nursing employment is also not very responsive to changes in SOP, with only small effects found from switching among some of the more restrictive SOP environments and no effect for the move to FPA. The effects of SOP on wages and earnings are uniformly negative but mostly statistically insignificant. There is evidence that weekly hours of work in the primary job and total hours of work across all jobs are higher in full practice authority states. In addition, SOP matters significantly for self-employment status, with nurses in full practice authority states much more likely to be self-employed by a range of 6-7 percentage points for APRNs and 7 to 10 percentage points for NPs. There is also some evidence that outside options are important with APRNs who live on the border of less restrictive states being more likely to cross a state border for work.

These results are in agreement with Kleiner et al. (2016) for work hours and wages, although our findings are not in support of the results by Perry (2012) on residence migration. 
And while not directly comparable, our results for probability of employment are also not in support of that of McMichael (2018) and Xue et al. (2018) for aggregate employment levels. We caution that some of these previous studies use different classifications of the SOP laws which makes comparison of results challenging. We argue that practice authority and prescription authority should be used in conjunction with each other in order to best reflect the overall practice environment under which APRNs practice.

The labor market effects are only one aspect of the debate surrounding the movement towards full practice authority and policy makers need to consider the effects on health outcomes, access to care, and costs in their deliberations. A growing body of research shows that allowing APRNs to practice to the full extent of their training without legislated oversight restrictions results in health outcomes that are either no different or slightly better than physicians' care, with lower costs, and more patient access (Adams and Markowitz, 2018). The primary conclusion from this paper is that changing the restrictiveness of SOP laws will not be disruptive to local labor markets, but can increase hours of work and self-employment, and may even increase the local workforce if the change to full practice authority reduces cross-state commuting as evidenced here (although while potentially decreasing the corresponding crossborder workforce in the process). Combined, these effects can have implications for patient access to providers. Yet, there is still more to be learned. The possible spill-over effects of full practice authority for APRNs on the labor supplies of physicians and physician assistants (PAs) are unknown at this point. More research is needed on the substitutability/complementarity between APRNs, PAs, and primary care physicians, and how the restrictiveness of SOP laws for APRNs and PAs affect these relationships. This is certainly an important direction for future research. 


\section{References}

Adams, E. K., \& Markowitz, S. (2018). Improving efficiency in the health-care system: Removing anticompetitive barriers for advanced practice registered nurses and physician assistants. Policy Proposal, 8, 9-13.

Bindman, A. B. (2013). Using the National Provider Identifier for health care workforce evaluation. Medicare \& Medicaid Research Review, 3(3).

DePasquale, C., \& Stange, K. (2016). Labor supply effects of occupational regulation: Evidence from the nurse licensure compact (No. w22344). National Bureau of Economic Research.

Kleiner, M. M., Marier, A., Park, K. W., \& Wing, C. (2016). Relaxing occupational licensing requirements: Analyzing wages and prices for a medical service. The Journal of Law and Economics, 59(2), 261-291.

Kurtzman, E. T., Barnow, B. S., Johnson, J. E., Simmens, S. J., Infeld, D. L., \& Mullan, F. (2017). Does the regulatory environment affect nurse practitioners' patterns of practice or quality of care in health centers?. Health services research, 52, 437-458.

Markowitz, S., Adams, E. K., Lewitt, M. J., \& Dunlop, A. L. (2017). Competitive effects of scope of practice restrictions: Public health or public harm?. Journal of Health Economics, 55, 201-218.

Martin, B., \& Alexander, M. (2019). The economic burden and practice restrictions associated with collaborative practice agreements: A national survey of advanced practice registered nurses. Journal of Nursing Regulation, 9(4), 22-30.

Martin, A. B., Hartman, M., Washington, B., Catlin, A., \& National Health Expenditure Accounts Team. National Health Expenditure Accounts Team. (2019). National Health Care Spending In 2017: Growth Slows To Post-Great Recession Rates; Share Of GDP Stabilizes. Health Affairs, 38(1):96-106.

McMichael, B. J. (2018). Beyond Physicians: The effect of licensing and liability laws on the supply of nurse practitioners and physician assistants. Journal of Empirical Legal Studies, 15(4), 732-771.

OECD (2018). Spending on Health: Latest Trends. Available at http://www.oecd.org/health/health-systems/Health-Spending-Latest-Trends-Brief.pdf.

Perry, J. J. (2012). State-granted practice authority: Do nurse practitioners vote with their feet?. Nursing research and practice, 2012. PMCID: PMC3512315.

Phillips, S. J. (2020). Annual APRN Legislative Update. The Nurse Practitioner.

Reagan, P. B., \& Salsberry, P. J. (2013). The effects of state-level scope-of-practice regulations on the number and growth of nurse practitioners. Nursing Outlook, 61(6), 392-399. 
Richards, M. R., \& Polsky, D. (2016). Influence of provider mix and regulation on primary care services supplied to US patients. Health Economics, Policy and Law, 11(2), 193-213.

Stange K. "How does provider supply and regulation influence health care markets? Evidence from nurse practitioners and physician assistants.” Journal of Health Economics. 2014; 33:127.

Timmons, Edward J. "The effects of expanded nurse practitioner and physician assistant scope of practice on the cost of Medicaid patient care." Health Policy 121.2 (2017): 189-196.

Traczynski, J., \& Udalova, V. (2018). Nurse practitioner independence, health care utilization, and health outcomes. Journal of Health Economics, 58, 90-109.

Wing, C., \& Marier, A. (2014). Effects of occupational regulations on the cost of dental services: evidence from dental insurance claims. Journal of Health Economics, 34, 131-143.

Xue, Y., Kannan, V., Greener, E., Smith, J. A., Brasch, J., Johnson, B. A., \& Spetz, J. (2018). Full scope-of-practice regulation is associated with higher supply of nurse practitioners in rural and primary care health professional shortage counties. Journal of Nursing Regulation, 8(4), 513. 
Figure 1: Scope of Practice Laws Over Time
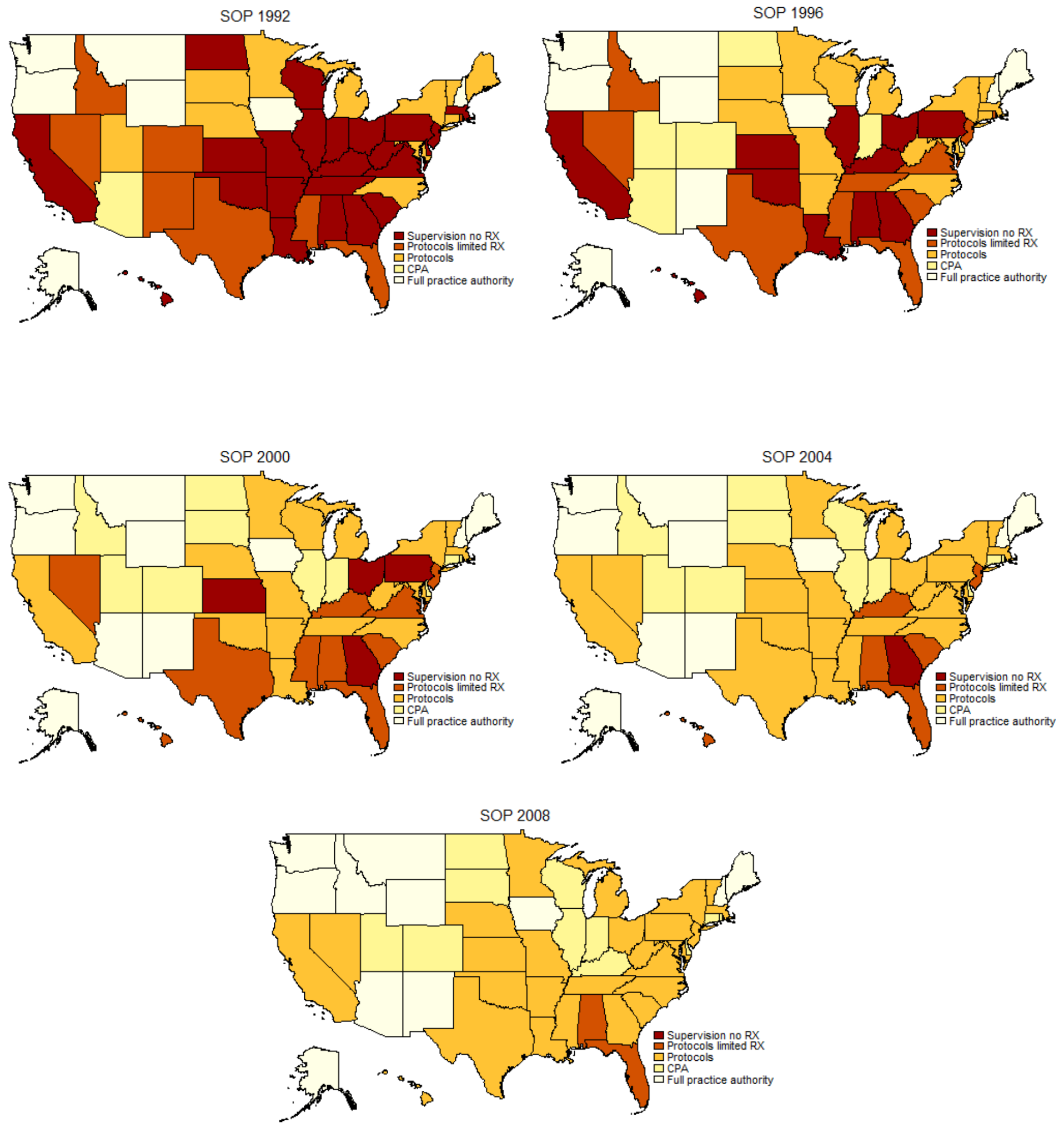
Figure 2: Trends in Average Outcomes
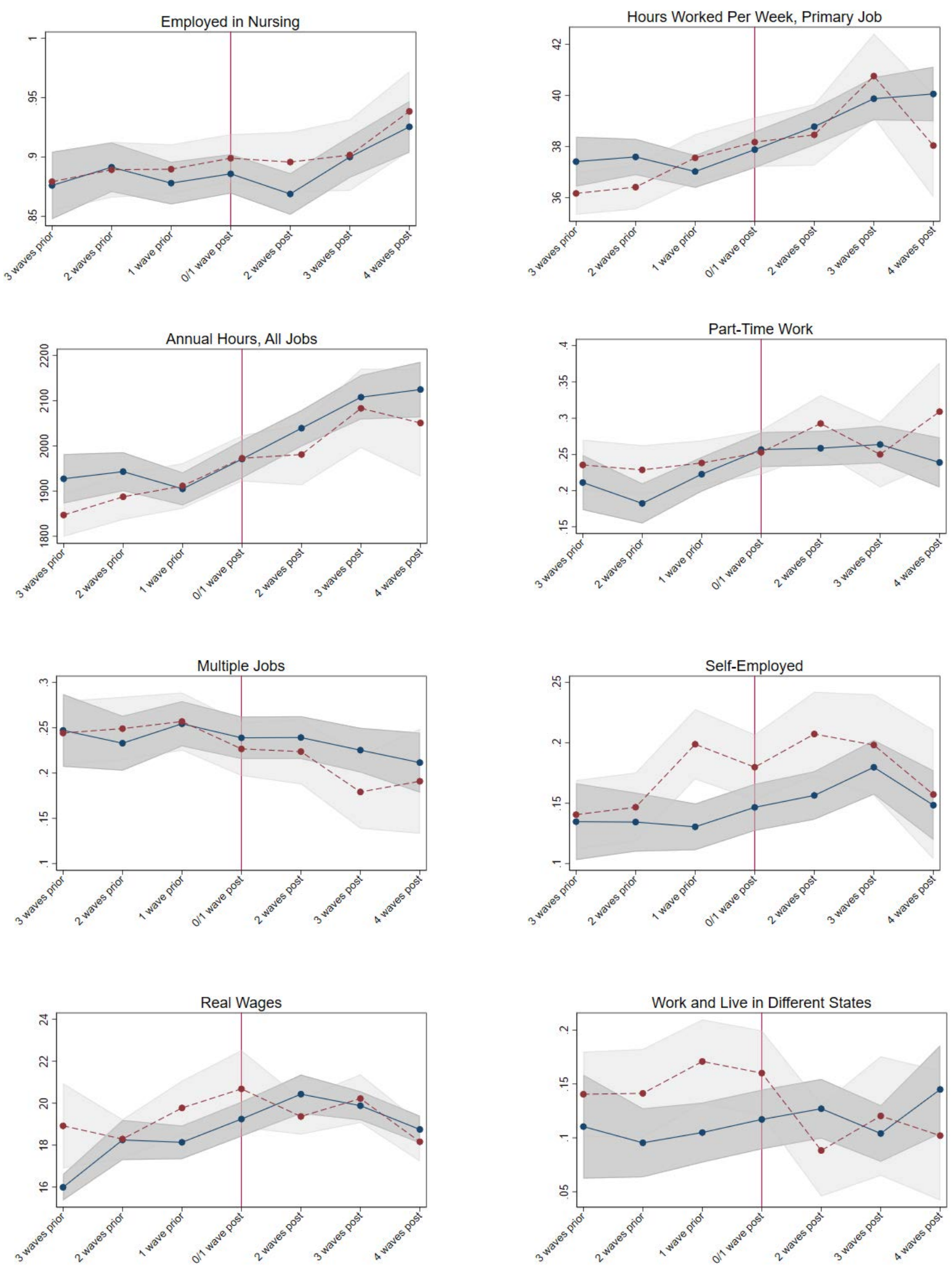

Note: Means and standard errors presented. Trends for the control states are based on randomly assigned dates of the event. Three year gap between waves. Event reflects any change in SOP law. The number of states contributing data to each wave from $3^{\text {th }}$ wave prior to $4^{\text {th }}$ wave post is $7,16,28,28,27,21$, and 12 respectively. 
Figure 3: Event Study
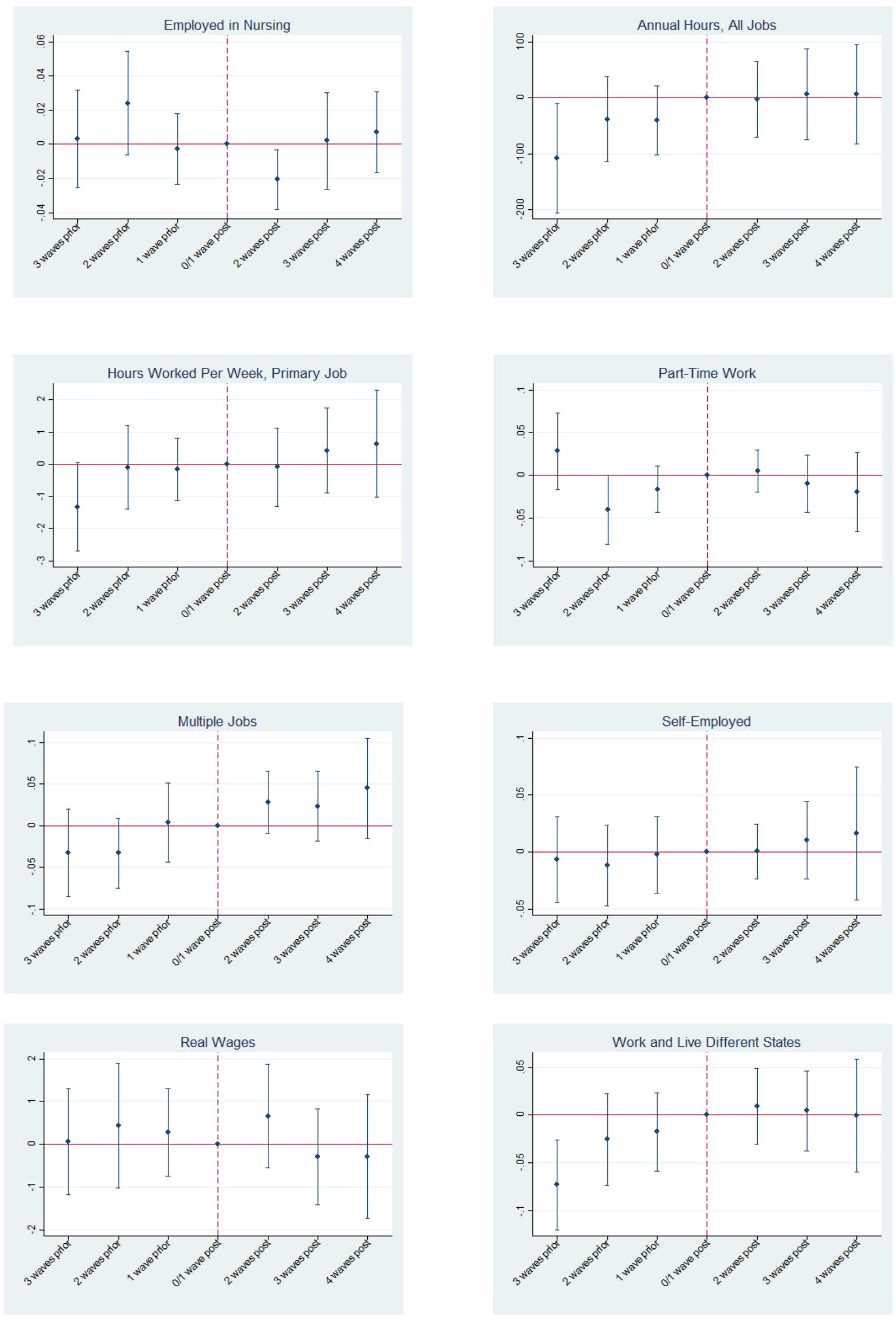

Note: Three year gap between waves. Regressions include individual characteristics, employment setting, county characteristics, state and year fixed effects. Standard errors are clustered by state of work/residence. Event reflects any change in SOP law. The number of states contributing data to each wave from $3^{\text {th }}$ wave prior to $4^{\text {th }}$ wave post is $7,16,28,28,27,21$, and 12 , respectively. 
Table 1: Means

\begin{tabular}{|l|c|c|}
\hline & APRNs & NPs \\
\hline Dependent Variables & & \\
\hline Employed_current year sample & 0.89 & 0.90 \\
\hline Employed_current and past year sample & 0.89 & 0.90 \\
\hline Weekly hours of work, primary job & 38.19 & 37.23 \\
\hline Annual hours of work, all jobs & 1980 & 1970 \\
\hline Works part-time & 0.24 & 0.27 \\
\hline Holds multiple jobs & 0.23 & 0.25 \\
\hline Self-employed & 0.16 & 0.13 \\
\hline Real hourly wages & 19.11 & 17.78 \\
\hline Real annual earnings & 34349 & 30914 \\
\hline Commute across state line for work-current year sample & 0.14 & 0.14 \\
\hline Commute across state line for work—current and past year sample & 0.14 & 0.14 \\
\hline Change work states in adjacent years & 0.05 & 0.05 \\
\hline & & \\
\hline State and County Variables & & \\
\hline Full practice authority & 0.16 & 0.20 \\
\hline CPA & 0.14 & 0.14 \\
\hline Protocols & 0.41 & 0.42 \\
\hline Protocols, limited RX & 0.14 & 0.13 \\
\hline Supervision, no RX & 0.15 & 0.10 \\
\hline Nurse Licensure Compact state & 0.17 & 0.20 \\
\hline MDs per 1000 county pop & 2.88 & 2.87 \\
\hline County unemployment & 5.33 & 5.27 \\
\hline & & \\
\hline Individual Characteristics & & \\
\hline Nurse Practitioner & 0.50 & -- \\
\hline Clinical Nurse Specialist & 0.34 & -- \\
\hline Nurse Anesthetist & 0.17 & -- \\
\hline Nurse Midwife & 0.06 & -- \\
\hline Male & 0.11 & 0.06 \\
\hline Non-white race & 0.10 & 0.11 \\
\hline Married & 0.71 & 0.72 \\
\hline Divorced & 0.17 & 0.16 \\
\hline Single & 0.12 & 0.11 \\
\hline Young children in house & 0.15 & 0.15 \\
\hline Older children in house & 0.34 & 0.35 \\
\hline
\end{tabular}




\begin{tabular}{|l|c|c|}
\hline Age $<30$ & 0.04 & 0.04 \\
\hline Age 30-39 & 0.22 & 0.22 \\
\hline Age 40-49 & 0.37 & 0.37 \\
\hline Age 50-59 & 0.29 & 0.29 \\
\hline Age 60 and up & 0.09 & 0.07 \\
\hline Age missing & 0.005 & 0.005 \\
\hline Race missing & 0.02 & 0.02 \\
\hline Children in house missing & 0.01 & 0.01 \\
\hline Marital status missing & 0.01 & 0.01 \\
\hline & & \\
\hline Employment Setting & & \\
\hline Hospital & 0.46 & 0.32 \\
\hline Nursing Home/Extended Care & 0.03 & 0.03 \\
\hline Nursing Education & 0.09 & 0.07 \\
\hline Community and Public Health & 0.11 & 0.14 \\
\hline School Health & 0.04 & 0.06 \\
\hline Occupation Health & 0.01 & 0.02 \\
\hline Ambulatory Care & 0.22 & 0.32 \\
\hline All other settings & 0.04 & 0.04 \\
\hline
\end{tabular}

Note: $\mathrm{N}=11,917$ for APRNs and N=5,929 for NPs for all state, county, individual and employment variables. Ns for the dependent variables are shown in the tables below. 
Table 2: Means of Dependent Variables by SOP Law Classification

\begin{tabular}{|l|c|c|c|c|c|}
\hline & $\begin{array}{c}\text { Full } \\
\text { practice } \\
\text { authority }\end{array}$ & CPA & Protocols & $\begin{array}{c}\text { Protocols, } \\
\text { limited } \\
\text { RX }\end{array}$ & $\begin{array}{c}\text { Supervision, } \\
\text { no RX }\end{array}$ \\
\hline $\begin{array}{l}\text { Employed_current year } \\
\text { sample }\end{array}$ & 0.89 & 0.90 & 0.89 & 0.89 & 0.87 \\
\hline $\begin{array}{l}\text { Employed_current and past } \\
\text { year sample }\end{array}$ & 0.90 & 0.90 & 0.89 & 0.89 & 0.87 \\
\hline $\begin{array}{l}\text { Weekly hours of work, } \\
\text { primary job }\end{array}$ & 38.10 & 38.43 & 38.57 & 38.32 & 36.95 \\
\hline $\begin{array}{l}\text { Annual hours of work, all } \\
\text { jobs }\end{array}$ & 1977 & 1994 & 2011 & 1972 & 1905 \\
\hline Works part-time & 0.27 & 0.25 & 0.24 & 0.20 & 0.23 \\
\hline Holds multiple jobs & 0.22 & 0.22 & 0.24 & 0.23 & 0.25 \\
\hline Self-employed & 0.20 & 0.14 & 0.16 & 0.16 & 0.12 \\
\hline Real hourly wages & 18.86 & 19.03 & 19.92 & 18.73 & 17.61 \\
\hline Real annual earnings & 33650 & 34205 & 36147 & 33780 & 30931 \\
\hline $\begin{array}{l}\text { Commute across state line for } \\
\text { work-current year sample }\end{array}$ & 0.11 & 0.09 & 0.16 & 0.13 & 0.14 \\
\hline $\begin{array}{l}\text { Commute across state line for } \\
\text { work—current and past year } \\
\text { sample }\end{array}$ & 0.11 & 0.09 & 0.16 & 0.15 & 0.14 \\
\hline $\begin{array}{l}\text { Change work states in } \\
\text { adjacent years }\end{array}$ & 0.06 & 0.04 & 0.04 & 0.07 & 0.06 \\
\hline
\end{tabular}


Table 3: Number of States in Scope of Practice Laws Categories, by Survey Date

\begin{tabular}{|l|c|c|c|c|c|}
\hline & 1992 & 1996 & 2000 & 2004 & 2008 \\
\hline Full practice authority & 7 & 10 & 11 & 11 & 12 \\
\hline CPA & 1 & 6 & 10 & 11 & 11 \\
\hline Protocols & 12 & 14 & 16 & 22 & 26 \\
\hline Protocols, limited RX & 8 & 10 & 10 & 6 & 2 \\
\hline Supervision, no RX & 23 & 11 & 4 & 1 & 0 \\
\hline \hline
\end{tabular}


Table 4: Effect of SOP laws on Probability of Employment in Nursing

\begin{tabular}{|c|c|c|c|c|c|c|c|c|}
\hline & $\begin{array}{c}\text { All } \\
\text { APRNs }\end{array}$ & $\begin{array}{c}\text { All } \\
\text { APRNs }\end{array}$ & $\begin{array}{c}\text { All } \\
\text { APRNs }\end{array}$ & $\begin{array}{c}\text { All } \\
\text { APRNs }\end{array}$ & $\begin{array}{l}\text { NPs } \\
\text { Only }\end{array}$ & $\begin{array}{l}\text { NPs } \\
\text { Only }\end{array}$ & $\begin{array}{l}\text { NPs } \\
\text { Only }\end{array}$ & $\begin{array}{l}\text { NPs } \\
\text { Only }\end{array}$ \\
\hline & $\begin{array}{c}\text { Current } \\
\text { year } \\
\text { sample }\end{array}$ & $\begin{array}{c}\text { Current } \\
\text { and } \\
\text { past } \\
\text { year } \\
\text { sample } \\
\end{array}$ & $\begin{array}{c}\text { Current } \\
\text { year } \\
\text { sample }\end{array}$ & $\begin{array}{c}\text { Current } \\
\text { and } \\
\text { past } \\
\text { year } \\
\text { sample } \\
\end{array}$ & $\begin{array}{c}\text { Current } \\
\text { year } \\
\text { sample }\end{array}$ & $\begin{array}{c}\text { Current } \\
\text { and } \\
\text { past } \\
\text { year } \\
\text { sample } \\
\end{array}$ & $\begin{array}{c}\text { Current } \\
\text { year } \\
\text { sample }\end{array}$ & $\begin{array}{c}\text { Current } \\
\text { and } \\
\text { past } \\
\text { year } \\
\text { sample }\end{array}$ \\
\hline Reside: CPA & $\begin{array}{c}0.029 \\
(0.032)\end{array}$ & $\begin{array}{c}0.027 \\
(0.027) \\
\end{array}$ & $\begin{array}{c}0.031 \\
(0.031)\end{array}$ & $\begin{array}{c}0.026 \\
(0.027) \\
\end{array}$ & $\begin{array}{c}0.004 \\
(0.030) \\
\end{array}$ & $\begin{array}{c}0.011 \\
(0.026) \\
\end{array}$ & $\begin{array}{l}-0.001 \\
(0.031) \\
\end{array}$ & $\begin{array}{c}0.007 \\
(0.026) \\
\end{array}$ \\
\hline Reside: Protocols & $\begin{array}{c}0.007 \\
(0.034)\end{array}$ & $\begin{array}{c}0.014 \\
(0.027)\end{array}$ & $\begin{array}{c}0.010 \\
(0.033)\end{array}$ & $\begin{array}{c}0.014 \\
(0.026)\end{array}$ & $\begin{array}{c}0.003 \\
(0.034)\end{array}$ & $\begin{array}{c}0.022 \\
(0.026)\end{array}$ & $\begin{array}{l}-0.006 \\
(0.034)\end{array}$ & $\begin{array}{c}0.015 \\
(0.026)\end{array}$ \\
\hline $\begin{array}{l}\text { Reside: Protocols, limited } \\
\text { RX }\end{array}$ & $\begin{array}{c}0.042 \\
(0.037)\end{array}$ & $\begin{array}{c}0.039 \\
(0.029)\end{array}$ & $\begin{array}{c}0.045 \\
(0.036)\end{array}$ & $\begin{array}{c}0.039 \\
(0.029)\end{array}$ & $\begin{array}{c}0.052 \\
(0.038)\end{array}$ & $\begin{array}{l}0.058^{* *} \\
(0.028)\end{array}$ & $\begin{array}{c}0.044 \\
(0.039)\end{array}$ & $\begin{array}{l}0.051^{*} \\
(0.029)\end{array}$ \\
\hline Reside: Supervision, no RX & $\begin{array}{c}0.010 \\
(0.036)\end{array}$ & $\begin{array}{c}0.010 \\
(0.029)\end{array}$ & $\begin{array}{c}0.014 \\
(0.035)\end{array}$ & $\begin{array}{c}0.011 \\
(0.029)\end{array}$ & $\begin{array}{l}-0.007 \\
(0.038)\end{array}$ & $\begin{array}{c}0.011 \\
(0.029)\end{array}$ & $\begin{array}{c}-0.020 \\
(0.040)\end{array}$ & $\begin{array}{c}0.001 \\
(0.030)\end{array}$ \\
\hline Border less restrictive & & & $\begin{array}{c}0.009 \\
(0.010)\end{array}$ & $\begin{array}{c}0.013 \\
(0.009)\end{array}$ & & & $\begin{array}{c}0.019 \\
(0.013)\end{array}$ & $\begin{array}{c}0.015 \\
(0.011)\end{array}$ \\
\hline $\begin{array}{l}\text { Border same or more } \\
\text { restrictive }\end{array}$ & & & $\begin{array}{c}0.013 \\
(0.011)\end{array}$ & $\begin{array}{c}0.015 \\
(0.010) \\
\end{array}$ & & & $\begin{array}{c}-0.002 \\
(0.011) \\
\end{array}$ & $\begin{array}{c}0.001 \\
(0.009) \\
\end{array}$ \\
\hline $\begin{array}{l}\text { Nurse Licensure Compact } \\
\text { state }\end{array}$ & $\begin{array}{l}0.018^{*} \\
(0.009)\end{array}$ & $\begin{array}{c}0.014^{*} \\
(0.008)\end{array}$ & $\begin{array}{l}0.019^{* *} \\
(0.009)\end{array}$ & $\begin{array}{c}0.015^{*} \\
(0.008)\end{array}$ & $\begin{array}{l}0.047^{* * *} \\
(0.013)\end{array}$ & $\begin{array}{l}0.033^{* * *} \\
(0.011)\end{array}$ & $\begin{array}{l}0.048^{* * *} \\
(0.013)\end{array}$ & $\begin{array}{l}0.033^{* * * *} \\
(0.011)\end{array}$ \\
\hline MDs per 1000 county pop & $\begin{array}{l}-0.001 \\
(0.001)\end{array}$ & $\begin{array}{l}-0.002 \\
(0.001)\end{array}$ & $\begin{array}{l}-0.001 \\
(0.001)\end{array}$ & $\begin{array}{l}-0.001 \\
(0.001)\end{array}$ & $\begin{array}{l}-0.000 \\
(0.002)\end{array}$ & $\begin{array}{l}-0.001 \\
(0.002)\end{array}$ & $\begin{array}{l}-0.000 \\
(0.002)\end{array}$ & $\begin{array}{l}-0.001 \\
(0.002)\end{array}$ \\
\hline County unemployment & $\begin{array}{c}0.002 \\
(0.002)\end{array}$ & $\begin{array}{c}0.001 \\
(0.002)\end{array}$ & $\begin{array}{c}0.002 \\
(0.002)\end{array}$ & $\begin{array}{c}0.001 \\
(0.002)\end{array}$ & $\begin{array}{l}0.006^{* *} \\
(0.003)\end{array}$ & $\begin{array}{c}0.004 \\
(0.002)\end{array}$ & $\begin{array}{l}0.006^{* *} \\
(0.003)\end{array}$ & $\begin{array}{c}0.003 \\
(0.002)\end{array}$ \\
\hline Clinical Nurse Specialist & $\begin{array}{c}-0.004 \\
(0.005)\end{array}$ & $\begin{array}{c}-0.004 \\
(0.005) \\
\end{array}$ & $\begin{array}{c}-0.004 \\
(0.005)\end{array}$ & $\begin{array}{c}-0.004 \\
(0.005) \\
\end{array}$ & & & & \\
\hline Nurse Anesthetist & $\begin{array}{c}0.011 \\
(0.008)\end{array}$ & $\begin{array}{c}0.002 \\
(0.008)\end{array}$ & $\begin{array}{c}0.012 \\
(0.009)\end{array}$ & $\begin{array}{c}0.002 \\
(0.008)\end{array}$ & & & & \\
\hline Nurse Midwife & $\begin{array}{c}0.000 \\
(0.009)\end{array}$ & $\begin{array}{c}-0.011 \\
(0.008)\end{array}$ & $\begin{array}{c}0.002 \\
(0.010)\end{array}$ & $\begin{array}{c}-0.008 \\
(0.008)\end{array}$ & & & & \\
\hline Male & $\begin{array}{l}0.044^{* * *} \\
(0.008)\end{array}$ & $\begin{array}{l}0.039^{* * *} \\
(0.007)\end{array}$ & $\begin{array}{l}0.043^{* * *} \\
(0.008)\end{array}$ & $\begin{array}{l}0.038^{* * *} \\
(0.007)\end{array}$ & $\begin{array}{c}0.044^{* * *} \\
(0.013)\end{array}$ & $\begin{array}{c}0.033^{* * *} \\
(0.010)\end{array}$ & $\begin{array}{c}0.042^{* * *} \\
(0.013)\end{array}$ & 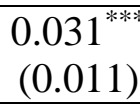 \\
\hline Non-white race & $\begin{array}{c}0.004 \\
(0.011)\end{array}$ & $\begin{array}{c}-0.002 \\
(0.010)\end{array}$ & $\begin{array}{c}0.004 \\
(0.011)\end{array}$ & $\begin{array}{c}-0.003 \\
(0.011)\end{array}$ & $\begin{array}{c}-0.008 \\
(0.011) \\
\end{array}$ & $\begin{array}{c}-0.014 \\
(0.010)\end{array}$ & $\begin{array}{c}-0.006 \\
(0.012) \\
\end{array}$ & $\begin{array}{c}-0.013 \\
(0.011)\end{array}$ \\
\hline Divorced & $\begin{array}{l}0.033^{* * *} \\
(0.009)\end{array}$ & $\begin{array}{l}0.033^{* * *} \\
(0.009)\end{array}$ & $\begin{array}{l}0.033^{* * *} \\
(0.009)\end{array}$ & $\begin{array}{l}0.034^{* * *} \\
(0.009)\end{array}$ & $\begin{array}{l}0.031^{* * *} \\
(0.010)\end{array}$ & $\begin{array}{l}0.033^{* * *} \\
(0.009)\end{array}$ & $\begin{array}{l}0.032^{* * *} \\
(0.010)\end{array}$ & $\begin{array}{l}0.034^{* * *} \\
(0.009)\end{array}$ \\
\hline Single & $\begin{array}{l}0.025^{* * *} \\
(0.008)\end{array}$ & $\begin{array}{c}0.026^{* * *} \\
(0.008)\end{array}$ & $\begin{array}{l}0.026^{* * *} \\
(0.008)\end{array}$ & $\begin{array}{c}0.026^{* * *} \\
(0.008)\end{array}$ & $\begin{array}{l}0.034^{* *} \\
(0.013)\end{array}$ & $\begin{array}{l}0.030^{* *} \\
(0.012)\end{array}$ & $\begin{array}{l}0.035^{* *} \\
(0.014)\end{array}$ & $\begin{array}{l}0.032^{* *} \\
(0.012)\end{array}$ \\
\hline Young children in house & $\begin{array}{c}-0.038^{* * * *} \\
(0.010)\end{array}$ & $\begin{array}{c}-0.037^{* * * *} \\
(0.010)\end{array}$ & $\begin{array}{c}-0.038^{* * * *} \\
(0.010)\end{array}$ & $\begin{array}{c}-0.038^{* * * *} \\
(0.010)\end{array}$ & $\begin{array}{c}-0.055^{* * *} \\
(0.013)\end{array}$ & $\begin{array}{c}-0.056^{* * *} \\
(0.012)\end{array}$ & $\begin{array}{c}-0.057^{* * *} \\
(0.013)\end{array}$ & $\begin{array}{c}-0.058^{* * *} \\
(0.013)\end{array}$ \\
\hline Older children in house & 0.009 & 0.009 & 0.009 & 0.008 & 0.011 & 0.009 & 0.010 & 0.008 \\
\hline
\end{tabular}




\begin{tabular}{|l|c|c|c|c|c|c|c|c|}
\hline & $(0.007)$ & $(0.006)$ & $(0.007)$ & $(0.006)$ & $(0.008)$ & $(0.007)$ & $(0.008)$ & $(0.007)$ \\
\hline Age $<30$ & $0.302^{* * *}$ & $0.261^{* * *}$ & $0.302^{* * *}$ & $0.261^{* * *}$ & $0.299^{* * *}$ & $0.268^{* * *}$ & $0.299^{* * *}$ & $0.269^{* * *}$ \\
& $(0.025)$ & $(0.023)$ & $(0.025)$ & $(0.023)$ & $(0.028)$ & $(0.024)$ & $(0.028)$ & $(0.024)$ \\
\hline Age 30-39 & $0.297^{* * *}$ & $0.269^{* * *}$ & $0.299^{* * *}$ & $0.272^{* * *}$ & $0.290^{* * *}$ & $0.261^{* * *}$ & $0.293^{* * *}$ & $0.265^{* * *}$ \\
& $(0.019)$ & $(0.017)$ & $(0.018)$ & $(0.017)$ & $(0.023)$ & $(0.020)$ & $(0.023)$ & $(0.021)$ \\
\hline Age 40-49 & $0.287^{* * *}$ & $0.263^{* * *}$ & $0.289^{* * *}$ & $0.265^{* * *}$ & $0.284^{* * *}$ & $0.260^{* * *}$ & $0.287^{* * *}$ & $0.262^{* * *}$ \\
& $(0.018)$ & $(0.016)$ & $(0.017)$ & $(0.016)$ & $(0.022)$ & $(0.020)$ & $(0.023)$ & $(0.020)$ \\
\hline Age 50-59 & $0.253^{* * *}$ & $0.236^{* * *}$ & $0.256^{* * *}$ & $0.239^{* * *}$ & $0.260^{* * *}$ & $0.236^{* * *}$ & $0.262^{* * *}$ & $0.238^{* * *}$ \\
& $(0.016)$ & $(0.016)$ & $(0.016)$ & $(0.015)$ & $(0.021)$ & $(0.019)$ & $(0.021)$ & $(0.019)$ \\
\hline N & 13457 & 26729 & 13337 & 26462 & 6614 & 13139 & 6551 & 12998 \\
\hline \hline
\end{tabular}

Notes: Clustered standard errors in parentheses based on state of residence. All models also include indicator variables for missing values for age, race, marital status and children, state of residence fixed effects and year fixed effects.

${ }^{*} p<0.10,{ }^{* *} p<0.05,{ }^{* * *} p<0.01$ 
Table 5: Effect of SOP laws on Work Hours, Multiple Jobs, and Self-Employment Among Workers

\begin{tabular}{|c|c|c|c|c|c|}
\hline Panel A: All APRNs & $\begin{array}{c}\text { Hours per } \\
\text { week, } \\
\text { primary job }\end{array}$ & $\begin{array}{c}\text { Annual } \\
\text { hours, all } \\
\text { jobs }\end{array}$ & $\begin{array}{l}\text { Part-time, } \\
\text { primary job }\end{array}$ & $\begin{array}{c}\text { Holds } \\
\text { multiple } \\
\text { jobs }\end{array}$ & $\begin{array}{c}\text { Self- } \\
\text { employed }\end{array}$ \\
\hline Work: CPA & $\begin{array}{l}-1.649^{* *} \\
(0.790)\end{array}$ & $\begin{array}{l}-106.755^{* * *} \\
(37.707)\end{array}$ & $\begin{array}{c}0.002 \\
(0.048)\end{array}$ & $\begin{array}{c}0.031 \\
(0.029)\end{array}$ & $\begin{array}{l}-0.063^{* * *} \\
(0.023)\end{array}$ \\
\hline Work: Protocols & $\begin{array}{l}-1.150 \\
(0.826)\end{array}$ & $\begin{array}{l}-67.393 \\
(41.034)\end{array}$ & $\begin{array}{c}0.002 \\
(0.043)\end{array}$ & $\begin{array}{c}0.028 \\
(0.033)\end{array}$ & $\begin{array}{l}-0.065^{* * *} \\
(0.023)\end{array}$ \\
\hline $\begin{array}{l}\text { Work: Protocols, limited } \\
\text { RX }\end{array}$ & $\begin{array}{l}-1.075 \\
(0.876)\end{array}$ & $\begin{array}{l}-99.796^{* *} \\
(43.016)\end{array}$ & $\begin{array}{l}-0.012 \\
(0.045)\end{array}$ & $\begin{array}{c}0.031 \\
(0.036)\end{array}$ & $\begin{array}{l}-0.071^{* * *} \\
(0.022)\end{array}$ \\
\hline $\begin{array}{l}\text { Work: Supervision, no } \\
\text { RX }\end{array}$ & $\begin{array}{l}-2.005^{* *} \\
(0.954)\end{array}$ & $\begin{array}{c}-134.895^{* *} \\
(52.818)\end{array}$ & $\begin{array}{c}0.007 \\
(0.047)\end{array}$ & $\begin{array}{c}0.015 \\
(0.042)\end{array}$ & $\begin{array}{c}-0.069^{* *} \\
(0.027)\end{array}$ \\
\hline $\begin{array}{l}\text { Nurse licensure compact, } \\
\text { state of work }\end{array}$ & $\begin{array}{c}0.676 \\
(0.404)\end{array}$ & $\begin{array}{c}7.007 \\
(24.131)\end{array}$ & $\begin{array}{l}-0.007 \\
(0.017)\end{array}$ & $\begin{array}{c}0.009 \\
(0.015)\end{array}$ & $\begin{array}{l}-0.001 \\
(0.013)\end{array}$ \\
\hline $\begin{array}{l}\text { MDs per } 1000 \text { pop, } \\
\text { county of work }\end{array}$ & $\begin{array}{c}0.044 \\
(0.051)\end{array}$ & $\begin{array}{l}6.712^{* *} \\
(2.866)\end{array}$ & $\begin{array}{l}-0.001 \\
(0.002)\end{array}$ & $\begin{array}{l}-0.004^{* *} \\
(0.002)\end{array}$ & $\begin{array}{l}-0.005 \\
(0.003)\end{array}$ \\
\hline $\begin{array}{l}\text { Unemployment, county } \\
\text { of work }\end{array}$ & $\begin{array}{c}0.139 \\
(0.087)\end{array}$ & $\begin{array}{c}3.903 \\
(5.482)\end{array}$ & $\begin{array}{l}-0.007^{*} \\
(0.004)\end{array}$ & $\begin{array}{l}-0.004^{*} \\
(0.002)\end{array}$ & $\begin{array}{l}-0.001 \\
(0.002)\end{array}$ \\
\hline $\mathrm{N}$ & 11854 & 11168 & 11912 & 11879 & 11917 \\
\hline Panel B: NPs Only & $\begin{array}{c}\text { Hours per } \\
\text { week, } \\
\text { primary job }\end{array}$ & $\begin{array}{c}\text { Annual } \\
\text { hours, all } \\
\text { jobs }\end{array}$ & $\begin{array}{l}\text { Part-time, } \\
\text { primary job }\end{array}$ & $\begin{array}{c}\text { Holds } \\
\text { multiple } \\
\text { jobs }\end{array}$ & $\begin{array}{c}\text { Self- } \\
\text { employed }\end{array}$ \\
\hline Work: CPA & $\begin{array}{l}-1.599 \\
(1.448)\end{array}$ & $\begin{array}{l}-80.924^{*} \\
(45.041)\end{array}$ & $\begin{array}{c}0.025 \\
(0.073)\end{array}$ & $\begin{array}{l}-0.039 \\
(0.040)\end{array}$ & $\begin{array}{l}-0.103^{* * *} \\
(0.023)\end{array}$ \\
\hline Work: Protocols & $\begin{array}{l}-1.947 \\
(1.465)\end{array}$ & $\begin{array}{l}-83.973 \\
(53.803)\end{array}$ & $\begin{array}{c}0.096 \\
(0.064)\end{array}$ & $\begin{array}{c}0.015 \\
(0.052)\end{array}$ & $\begin{array}{c}-0.074^{* * *} \\
(0.022)\end{array}$ \\
\hline $\begin{array}{l}\text { Work: Protocols, limited } \\
\text { RX }\end{array}$ & $\begin{array}{l}-0.661 \\
(1.498)\end{array}$ & $\begin{array}{l}-24.014 \\
(53.205)\end{array}$ & $\begin{array}{c}0.030 \\
(0.064)\end{array}$ & $\begin{array}{l}-0.012 \\
(0.052)\end{array}$ & $\begin{array}{c}-0.106^{* * *} \\
(0.028)\end{array}$ \\
\hline $\begin{array}{l}\text { Work: Supervision, no } \\
\text { RX }\end{array}$ & $\begin{array}{l}-2.790^{*} \\
(1.554)\end{array}$ & $\begin{array}{c}-147.779^{* *} \\
(69.547)\end{array}$ & $\begin{array}{c}0.074 \\
(0.069)\end{array}$ & $\begin{array}{l}-0.020 \\
(0.064)\end{array}$ & $\begin{array}{l}-0.073^{*} \\
(0.037)\end{array}$ \\
\hline $\begin{array}{l}\text { Nurse licensure compact, } \\
\text { state of work }\end{array}$ & $\begin{array}{c}0.104 \\
(0.702)\end{array}$ & $\begin{array}{l}-16.673 \\
(36.490)\end{array}$ & $\begin{array}{c}0.008 \\
(0.026)\end{array}$ & $\begin{array}{l}-0.007 \\
(0.023)\end{array}$ & $\begin{array}{c}0.009 \\
(0.021)\end{array}$ \\
\hline $\begin{array}{l}\text { MDs per } 1000 \text { pop, } \\
\text { county of work }\end{array}$ & $\begin{array}{c}0.147 \\
(0.105)\end{array}$ & $\begin{array}{c}5.567 \\
(6.344)\end{array}$ & $\begin{array}{c}0.000 \\
(0.004)\end{array}$ & $\begin{array}{l}-0.003 \\
(0.003)\end{array}$ & $\begin{array}{l}-0.003 \\
(0.004)\end{array}$ \\
\hline $\begin{array}{l}\text { Unemployment, county } \\
\text { of work }\end{array}$ & $\begin{array}{c}0.167 \\
(0.132)\end{array}$ & $\begin{array}{c}6.368 \\
(6.144)\end{array}$ & $\begin{array}{l}-0.008^{*} \\
(0.004)\end{array}$ & $\begin{array}{c}-0.005 \\
(0.003)\end{array}$ & $\begin{array}{c}-0.002 \\
(0.002)\end{array}$ \\
\hline $\mathrm{N}$ & 5913 & 5541 & 5927 & 5910 & 5929 \\
\hline
\end{tabular}

Notes: Clustered standard errors in parentheses based on state of work. All models also include the individual characteristics shown in Table 2, indicator variables for missing values for age, race, marital status and children, indicators for employment setting, state of work fixed effects and year fixed effects.

${ }^{*} p<0.10,{ }^{* *} p<0.05,{ }^{* * *} p<0.01$ 
Table 6: Effect of SOP laws on Wages and Earnings

\begin{tabular}{|l|c|c|c|c|}
\hline Panel A: All APRNs & Real Wages & $\begin{array}{c}\text { Ln Real } \\
\text { Wages }\end{array}$ & $\begin{array}{c}\text { Real } \\
\text { Earnings }\end{array}$ & $\begin{array}{c}\text { Ln Real } \\
\text { Earnings }\end{array}$ \\
\hline Work: CPA & 0.280 & -0.022 & -2453.248 & -0.075 \\
& $(1.286)$ & $(0.052)$ & $(2203.200)$ & $(0.071)$ \\
\hline Work: Protocols & -0.271 & -0.035 & -1951.837 & -0.064 \\
& $(1.084)$ & $(0.051)$ & $(2233.838)$ & $(0.072)$ \\
\hline Work: Protocols, limited RX & -0.021 & -0.023 & -2103.806 & -0.062 \\
& $(1.121)$ & $(0.056)$ & $(2423.544)$ & $(0.078)$ \\
\hline Work: Supervision, no RX & 0.213 & -0.021 & -2367.068 & -0.081 \\
& $(1.221)$ & $(0.056)$ & $(2401.848)$ & $(0.080)$ \\
\hline Nurse licensure compact, state & 0.654 & 0.008 & 850.390 & 0.019 \\
of work & $(0.515)$ & $(0.015)$ & $(580.826)$ & $(0.021)$ \\
\hline MDs per 1000 pop, county of & 0.037 & 0.004 & 242.968 & $0.012^{* *}$ \\
work & $(0.089)$ & $(0.004)$ & $(172.934)$ & $(0.005)$ \\
\hline Unemployment, county of work & 0.069 & 0.002 & $156.731^{*}$ & $0.008 *$ \\
& $(0.086)$ & $(0.003)$ & $(87.390)$ & $(0.003)$ \\
\hline N & 11201 & 11201 & 11327 & 11327 \\
\hline \multicolumn{4}{|c|}{} & \\
\hline Panel B: NPs Only & Real Wages & Ln Real & Real & Ln Real \\
& & Wages & Earnings & Earnings \\
\hline Work: CPA & -1.941 & -0.098 & -3718.472 & -0.076 \\
& $(1.227)$ & $(0.071)$ & $(2840.407)$ & $(0.126)$ \\
\hline Work: Protocols & -2.111 & -0.101 & -4086.995 & -0.115 \\
& $(1.392)$ & $(0.076)$ & $(2851.739)$ & $(0.123)$ \\
\hline Work: Protocols, limited RX & $-2.398^{*}$ & -0.092 & -2422.726 & -0.056 \\
& $(1.422)$ & $(0.079)$ & $(3034.760)$ & $(0.130)$ \\
\hline Work: Supervision, no RX & -2.003 & -0.086 & -3491.051 & -0.099 \\
& $(1.637)$ & $(0.083)$ & $(3076.669)$ & $(0.134)$ \\
\hline Nurse licensure compact, state & 0.427 & -0.008 & -159.463 & -0.001 \\
of work & $(0.709)$ & $(0.023)$ & $(657.670)$ & $(0.033)$ \\
\hline MDs per 1000 pop, county of & 0.060 & 0.005 & $359.006^{* *}$ & $0.014^{* *}$ \\
work & $(0.085)$ & $(0.003)$ & $(168.891)$ & $(0.006)$ \\
\hline Unemployment, county of work & 0.039 & 0.003 & $228.194^{* *}$ & $0.011^{* *}$ \\
& $(0.133)$ & $(0.004)$ & $(101.123)$ & $(0.005)$ \\
\hline N & 5637 & 5637 & 5691 & 5691 \\
\hline \hline
\end{tabular}

Notes: Clustered standard errors in parentheses based on state of work. All models also include the individual characteristics shown in Table 2, indicator variables for missing values for age, race, marital status and children, indicators for employment setting, state of work fixed effects and year fixed effects.

${ }^{*} p<0.10,{ }^{* *} p<0.05,{ }^{* * *} p<0.01$ 
Table 7: Effect of SOP laws on Probability of Commuting Across State Lines, Border Residents

\begin{tabular}{|c|c|c|c|c|}
\hline Panel A: All APRNs & $\begin{array}{l}\text { Current year } \\
\text { sample }\end{array}$ & $\begin{array}{c}\text { Current and } \\
\text { past year } \\
\text { sample }\end{array}$ & $\begin{array}{l}\text { Current year } \\
\text { sample }\end{array}$ & $\begin{array}{c}\text { Current and } \\
\text { past year } \\
\text { sample }\end{array}$ \\
\hline Border less restrictive & $\begin{array}{l}0.054^{*} \\
(0.030)\end{array}$ & $\begin{array}{l}0.058^{* *} \\
(0.029)\end{array}$ & & \\
\hline $\begin{array}{l}\text { Reside: CPA and border less } \\
\text { restrictive }\end{array}$ & & & $\begin{array}{l}0.094^{* * *} \\
(0.033)\end{array}$ & $\begin{array}{l}0.093^{* * *} \\
(0.033)\end{array}$ \\
\hline $\begin{array}{l}\text { Reside: Protocols and border less } \\
\text { restrictive }\end{array}$ & & & $\begin{array}{c}0.089^{*} \\
(0.048)\end{array}$ & $\begin{array}{l}0.078^{*} \\
(0.045)\end{array}$ \\
\hline $\begin{array}{l}\text { Reside: Protocols, limited RX and } \\
\text { border less restrictive }\end{array}$ & & & $\begin{array}{c}0.034 \\
(0.032)\end{array}$ & $\begin{array}{c}0.078 \\
(0.047)\end{array}$ \\
\hline $\begin{array}{l}\text { Reside: Supervision, no RX and } \\
\text { border less restrictive }\end{array}$ & & & $\begin{array}{c}0.002 \\
(0.017)\end{array}$ & $\begin{array}{c}0.017 \\
(0.016)\end{array}$ \\
\hline Nurse licensure compact state & $\begin{array}{l}-0.009 \\
(0.022)\end{array}$ & $\begin{array}{l}-0.009 \\
(0.023)\end{array}$ & $\begin{array}{l}-0.004 \\
(0.022)\end{array}$ & $\begin{array}{l}-0.006 \\
(0.023)\end{array}$ \\
\hline MDs per 1000 pop & $\begin{array}{c}-0.016^{* * *} \\
(0.005)\end{array}$ & $\begin{array}{c}-0.016^{* * *} \\
(0.006)\end{array}$ & $\begin{array}{c}-0.016^{* * *} \\
(0.005)\end{array}$ & $\begin{array}{c}-0.016^{* * *} \\
(0.006)\end{array}$ \\
\hline County unemployment & $\begin{array}{l}-0.006 \\
(0.004)\end{array}$ & $\begin{array}{l}-0.005 \\
(0.004)\end{array}$ & $\begin{array}{l}-0.005 \\
(0.004)\end{array}$ & $\begin{array}{l}-0.005 \\
(0.004)\end{array}$ \\
\hline $\mathrm{N}$ & 5343 & 10534 & 5343 & 10534 \\
\hline \multicolumn{5}{|l|}{ Panel B: NPs Only } \\
\hline Border less restrictive & $\begin{array}{c}0.045 \\
(0.044)\end{array}$ & $\begin{array}{c}0.046 \\
(0.040)\end{array}$ & & \\
\hline $\begin{array}{l}\text { Reside: CPA and border less } \\
\text { restrictive }\end{array}$ & & & $\begin{array}{c}0.053 \\
(0.045)\end{array}$ & $\begin{array}{c}0.072 \\
(0.047)\end{array}$ \\
\hline $\begin{array}{l}\text { Reside: Protocols and border less } \\
\text { restrictive }\end{array}$ & & & $\begin{array}{c}0.081 \\
(0.059)\end{array}$ & $\begin{array}{c}0.060 \\
(0.053)\end{array}$ \\
\hline $\begin{array}{l}\text { Reside: Protocols, limited RX and } \\
\text { border less restrictive }\end{array}$ & & & $\begin{array}{l}-0.024 \\
(0.050)\end{array}$ & $\begin{array}{c}0.043 \\
(0.070)\end{array}$ \\
\hline $\begin{array}{l}\text { Reside: Supervision, no RX and } \\
\text { border less restrictive }\end{array}$ & & & $\begin{array}{l}-0.015 \\
(0.038)\end{array}$ & $\begin{array}{c}0.004 \\
(0.037)\end{array}$ \\
\hline $\begin{array}{l}\text { Nurse licensure compact, state of } \\
\text { work }\end{array}$ & $\begin{array}{l}-0.017 \\
(0.034)\end{array}$ & $\begin{array}{l}-0.026 \\
(0.033)\end{array}$ & $\begin{array}{l}-0.011 \\
(0.034)\end{array}$ & $\begin{array}{l}-0.022 \\
(0.033)\end{array}$ \\
\hline MDs per 1000 pop, county of work & $\begin{array}{c}-0.022^{* * *} \\
(0.007)\end{array}$ & $\begin{array}{c}-0.020^{* *} \\
(0.008)\end{array}$ & $\begin{array}{c}-0.022^{* * *} \\
(0.007)\end{array}$ & $\begin{array}{c}-0.020^{* *} \\
(0.008)\end{array}$ \\
\hline Unemployment, county of work & $\begin{array}{l}-0.009^{*} \\
(0.005)\end{array}$ & $\begin{array}{c}-0.011^{* *} \\
(0.005)\end{array}$ & $\begin{array}{l}-0.009^{*} \\
(0.005)\end{array}$ & $\begin{array}{l}-0.011^{* *} \\
(0.005)\end{array}$ \\
\hline $\mathrm{N}$ & 2624 & 5172 & 2624 & 5172 \\
\hline
\end{tabular}

Notes: Clustered standard errors in parentheses based on state of work. All models also include the individual characteristics shown in Table 2, indicator variables for missing values for age, race, marital status and children, indicators for employment setting, state of work fixed effects and year fixed effects. ${ }^{*} p<0.10,{ }^{* *} p<0.05,{ }^{* * *} p<0.01$ 
Table 8: Effect of SOP laws on Outcomes, Changing the Omitted Law Category

\begin{tabular}{|c|c|c|c|c|c|}
\hline Employment in nursing & $\begin{array}{c}\text { FPA } \\
\text { omitted }\end{array}$ & $\begin{array}{c}\text { CPA } \\
\text { omitted }\end{array}$ & $\begin{array}{c}\text { Protocols } \\
\text { omitted }\end{array}$ & $\begin{array}{c}\text { Protocols, } \\
\text { limited RX } \\
\text { omitted }\end{array}$ & $\begin{array}{c}\text { Supervision, } \\
\text { no RX } \\
\text { omitted }\end{array}$ \\
\hline Reside: Full practice authority & & $\begin{array}{l}-0.029 \\
(0.032)\end{array}$ & $\begin{array}{l}-0.007 \\
(0.034)\end{array}$ & $\begin{array}{l}-0.042 \\
(0.037)\end{array}$ & $\begin{array}{l}-0.010 \\
(0.036)\end{array}$ \\
\hline Reside: CPA & $\begin{array}{c}0.029 \\
(0.032)\end{array}$ & & $\begin{array}{l}0.022^{*} \\
(0.012)\end{array}$ & $\begin{array}{l}-0.013 \\
(0.013)\end{array}$ & $\begin{array}{c}0.020 \\
(0.013)\end{array}$ \\
\hline Reside: Protocols & $\begin{array}{c}0.007 \\
(0.034)\end{array}$ & $\begin{array}{l}-0.022^{*} \\
(0.012)\end{array}$ & & $\begin{array}{c}-0.035^{* * *} \\
(0.010)\end{array}$ & $\begin{array}{l}-0.002 \\
(0.009)\end{array}$ \\
\hline Reside: Protocols, limited RX & $\begin{array}{c}0.042 \\
(0.037)\end{array}$ & $\begin{array}{c}0.013 \\
(0.013)\end{array}$ & $\begin{array}{l}0.035^{* * *} \\
(0.010)\end{array}$ & & $\begin{array}{l}0.032^{* * *} \\
(0.012)\end{array}$ \\
\hline Reside: Supervision, no RX & $\begin{array}{c}0.010 \\
(0.036)\end{array}$ & $\begin{array}{l}-0.020 \\
(0.013)\end{array}$ & $\begin{array}{c}0.002 \\
(0.009)\end{array}$ & $\begin{array}{c}-0.032^{* * *} \\
(0.012)\end{array}$ & \\
\hline \multicolumn{6}{|l|}{$\begin{array}{l}\text { Hours per week, primary } \\
\text { job }\end{array}$} \\
\hline Work: Full practice authority & & $\begin{array}{l}1.649^{* *} \\
(0.790)\end{array}$ & $\begin{array}{c}1.150 \\
(0.826)\end{array}$ & $\begin{array}{c}1.075 \\
(0.876)\end{array}$ & $\begin{array}{l}2.005^{* *} \\
(0.954)\end{array}$ \\
\hline Work: CPA & $\begin{array}{l}-1.649^{* *} \\
(0.790)\end{array}$ & & $\begin{array}{l}-0.499 \\
(0.425)\end{array}$ & $\begin{array}{l}-0.574 \\
(0.464)\end{array}$ & $\begin{array}{c}0.356 \\
(0.550)\end{array}$ \\
\hline Work: Protocols & $\begin{array}{l}-1.150 \\
(0.826)\end{array}$ & $\begin{array}{c}0.499 \\
(0.425)\end{array}$ & & $\begin{array}{l}-0.074 \\
(0.427)\end{array}$ & $\begin{array}{l}0.856^{*} \\
(0.441)\end{array}$ \\
\hline Work: Protocols, limited RX & $\begin{array}{l}-1.075 \\
(0.876)\end{array}$ & $\begin{array}{c}0.574 \\
(0.464)\end{array}$ & $\begin{array}{c}0.074 \\
(0.427)\end{array}$ & & $\begin{array}{l}0.930^{*} \\
(0.554)\end{array}$ \\
\hline Work: Supervision, no RX & $\begin{array}{c}-2.005^{* *} \\
(0.954) \\
\end{array}$ & $\begin{array}{l}-0.356 \\
(0.550) \\
\end{array}$ & $\begin{array}{l}-0.856^{*} \\
(0.441) \\
\end{array}$ & $\begin{array}{l}-0.930^{*} \\
(0.554) \\
\end{array}$ & \\
\hline \multicolumn{6}{|l|}{ Self -employed } \\
\hline Work: Full practice authority & & $\begin{array}{l}0.063^{* * *} \\
(0.023)\end{array}$ & $\begin{array}{l}0.065^{* * *} \\
(0.023)\end{array}$ & $\begin{array}{l}0.071^{* * *} \\
(0.022)\end{array}$ & $\begin{array}{l}0.069^{* *} \\
(0.027)\end{array}$ \\
\hline Work: CPA & $\begin{array}{c}-0.063^{* * *} \\
(0.023)\end{array}$ & & $\begin{array}{c}0.001 \\
(0.015)\end{array}$ & $\begin{array}{c}0.008 \\
(0.014)\end{array}$ & $\begin{array}{c}0.006 \\
(0.019)\end{array}$ \\
\hline Work: Protocols & $\begin{array}{c}-0.065^{* * *} \\
(0.023)\end{array}$ & $\begin{array}{l}-0.001 \\
(0.015)\end{array}$ & & $\begin{array}{c}0.006 \\
(0.012)\end{array}$ & $\begin{array}{c}0.004 \\
(0.014)\end{array}$ \\
\hline Work: Protocols, limited RX & $\begin{array}{c}-0.071^{* * *} \\
(0.022)\end{array}$ & $\begin{array}{l}-0.008 \\
(0.014)\end{array}$ & $\begin{array}{l}-0.006 \\
(0.012)\end{array}$ & & $\begin{array}{l}-0.002 \\
(0.014)\end{array}$ \\
\hline Work: Supervision, no RX & $\begin{array}{l}-0.069^{* *} \\
(0.027)\end{array}$ & $\begin{array}{l}-0.006 \\
(0.019)\end{array}$ & $\begin{array}{l}-0.004 \\
(0.014)\end{array}$ & $\begin{array}{c}0.002 \\
(0.014)\end{array}$ & \\
\hline
\end{tabular}

Notes: Clustered standard errors in parentheses based on either state of residence or work. All models also include the county and individual characteristics shown in Table 2, indicator variables for missing values for age, race, marital status and children, indicators for employment setting (if applicable), state fixed effects and year fixed effects. ${ }^{*} p<0.10,{ }^{* *} p<0.05,{ }^{* * *} p<0.01$ 